Discussion Paper No. 743

\title{
AN EXPERIMENTAL STUDY OF PROCUREMENT AUCTIONS WITH ENDOGENOUS MINIMUM PRICES
}

\author{
Kenju Akai \\ Tatsuyoshi Saijo \\ Shigehiro Serizawa
}

June 2009

Revised July 2010

The Institute of Social and Economic Research Osaka University

6-1 Mihogaoka, Ibaraki, Osaka 567-0047, Japan 


\title{
An Experimental Study of Procurement Auctions with Endogenous Minimum Prices
}

\author{
Kenju Akai ${ }^{a, *}$, Tatsuyoshi Saijo ${ }^{\mathrm{a}, \dagger}$, Shigehiro Serizawa ${ }^{\mathrm{a}, \dagger}$ \\ ${ }^{a}$ Institute of Social and Economic Research, Osaka University, 6-1 Mihogaoka, Ibaragi, Osaka \\ 5670047, Japan
}

\begin{abstract}
Several European countries and many Japanese local governments began including endogenous minimum prices (EMPs) in first-price auctions (FPAs) in their public procurements. The EMP is calculated based on its relation to the average of all bids or to some lowest bids. Any bid lower than the EMP is considered abnormally low and is excluded from the procurement procedure. Producers who join this new auction institution have the incentive to raise their bids and pull up the EMP in order to exclude others. A theoretical analysis reveals that the EMP does not affect winning bids but changes the Nash equilibria of the standard FPA that does not have any minimum prices. A laboratory analysis reveals that the winning bids of this new auction institution (i) are close to the production cost and coincide with those of the standard FPA under the identical cost condition and (ii) are higher than the lowest production cost and those of the standard FPA under our different cost condition when subjects' identifications and bids are revealed.
\end{abstract}

JEL classification: C92; D44; L15

Key words: Public procurement; First-price auction; Experiment; Abnormally low tender; Endogenous minimum price

*This is revised version of "An Experimental Study of Japanese Procurement Auctions with Endogenous Minimum Prices" published in ISER Discussion Paper No. 743.

*Corresponding author: k-akai@iser.osaka-u.ac.jp, Institute of Social and Economic Research, Osaka University, 6-1 Mihogaoka, Ibaragi, Osaka 5670047, Japan. Tel.: +81-6-68798552; Fax: +81-6-6879-8584.

†E-mail: saijo@iser.osaka-u.ac.jp (T. Saijo), serizawa@iser.osaka-u.ac.jp (S. Serizawa) 


\section{INTRODUCTION}

In recent public procurements, several European countries and many Japanese local governments have introduced minimum prices that have been calculated based on their relation to the average of all bids or some lowest bids in first-price auctions (FPAs) ${ }^{1}$. In this auction institution, any bid lower than the minimum price is excluded and the winning bid is the lowest among bids higher than the minimum price. According to the European Commission's report (1999), Belgium, Italy, Portugal, Spain, and Greece recognize (and/or suspect) a tender as being abnormally low "if the price offered is less by a certain percentage than the average of the tenders submitted or discounts granted, with various differences in the percentage and/or calculation of the average".

Although there are several methods to calculate minimum prices, in this paper we refer to minimum prices based on their relation to the average of all bids or some lowest bids as endogenous minimum prices (EMPs); we investigate their performance using theory and laboratory experiment. Basically, the EMP excludes abnormally low bids that cannot satisfy the quality of public work that the auction authorities require. The EMP is, however, often criticized by legal and political sides as curbing fair competition. For instance, the European Court of Justice said that "tenders may not automatically be excluded if they deviate more than a fixed percentage rate from the average of all other tenders submitted ${ }^{2}$.

Since the EMP is determined by its relation to the average bids, producers who join this auction institution have an incentive to raise their bids and pull up the minimum price to exclude others and become a winner. In this case, the winning bid is likely to be higher than its cost which is the best outcome for the government and taxpayers to minimize their expenditure.

For example, let EMP $=0.8 \times$ average of the three lowest bids. This kind of method of calculation is popular among Japanese local governments. The ranking of bids is presented in Table 1. In this case, the EMP is $\$ 103$, the winner is Bidder 2, and the winning bid is $\$ 105$. However, if Bidder 3 whose bid is $\$ 130$ raises his/her bid to $\$ 149$, the EMP becomes $\$ 106$ and he/she can be the winner.

Table 1 is around here

Although this is a rough example, it indicates the risk of taxpayers wasting their money. Especially in Japan, the total contract price of public procurement for all local governments from 2005 to 2007 is approximately 24 trillion yen (229 billion US dollars) ${ }^{3}$, whereas that for the central government is about 7 trillion yen ( 67 billion US dollars $)^{4}$. Therefore, the EMP is likely to result in huge social losses in Japan. This situation would be more serious in the EU because the EU has a wider economy than Japan does. To confirm this, we theoretically analyze the Nash equilibria in the FPA with EMP. We find that the EMP does not affect the winning bids of the standard FPA that does not have any minimum prices but expands its Nash equilibria as including the Nash equilibria such that $b_{i}<c$, for some $i$.

\footnotetext{
${ }^{1}$ Ohno and Harada (2006) compare public procurement systems in Japan with systems in the US and the EU.

${ }^{2}$ Refer to Judgement of 18 June 1991 in case C-295/89 "Alonso"; judgement of 26 October 1995 in case C143/94 "Furlanis"; and judgement of 16 October 1997 in case C-304/96 "Genova".

${ }^{3} 1$ US dollar $=105$ Japanese yen.

${ }^{4}$ Original data are obtained from the websites of East Japan Construction Surety Co., Ltd; Hokkaido Construction Surety Co., Ltd; and West Japan Construction Surety Co., Ltd.
} 
To verify the above theoretical results, we use experimental methods that feature three treatment variables - minimum prices (the EMP vs. no-minimum price), production costs (identical vs. different), and the information of subjects' identifications and bids (disclosure vs. nondisclosure). In the identical cost condition, the winning bids in both the FPA with EMP and the standard FPA are consistent with the cost regardless of disclosing the information of subjects' identifications and bids. In the different cost condition, when the information of subjects' identifications and bids is disclosed, the winning bids of the FPA with EMP diverge from the lowest cost and are significantly higher than those of the standard FPA. In the latter condition, since most producers bid higher than their costs and the EMP becomes higher than the lowest cost, producers with the lowest cost bid higher prices than their costs not to be excluded by the EMP. Thus, winning bids become higher than the lowest cost.

We are only aware of two literatures that analyze the EMP. The first is Calveras et al. (2004), who theoretically show that even in the second-price auction, producers with a small amount of initial cash can make a profit by bidding low and declaring bankruptcy if the cost is found to be high. Under this assumption, they briefly suggest that the EMP employed in European countries does not work well. Second, Decarolis (2009) theoretically shows that the auction authorities prefer average bid auctions employed in European countries than the FPA when their monitoring cost is high, and empirically analyzes the monitoring cost in Italy. Therefore, our study is, to the best of our knowledge, the first experiment evaluating the performance of the EMP.

In the procurement auction experiments, when costs are independent private values, Cox et al. (1996) observe that too-low bids in the FPA lead to cost overruns when post-acution cost is uncertainty, and Brosig and Reiß (2007) show that bids are lower than the theoretical predictions. On the other hand, when the cost is common knowledge, Saijo et al. (1996), Dufwenberg and Gneezy (2002), Kawagoe (2003), and Dufwenberg and Gneezy (2004) find that the FPA mostly works well, except for the case in which they allow collusion or disclose losing bids. In Japan, since only local governments employ the EMP and their procurement auctions are held in a restricted area, the wages and rental costs of producing homogenous goods do not vary and the production cost is common knowledge among producers. Therefore, in this paper, we assume that goods are homogenous and those costs are common knowledge among producers; we then analyze the Nash equilibria ${ }^{5}$.

Nevertheless, in the procurement auction, the quality of public construction is a non-negligible issue. Optimal auction schemes considering quality have been studied by Sinclair-Desgagne (1990), Dasgupta and Spulber (1990), Che (1993), Von Ungern-Sternberg (1994), Manelli and Vincent (1995), and Naegelen (2002) ${ }^{6}$. They reveal that private information on producers' quality leads to the distortion of social welfare. This paper is, however, the first step towards evaluating the performance of the EMP. Therefore, we simplify our model setting to focus on price competition, and release our attention from quality ${ }^{7}$.

Apart from the procurement auction, from the viewpoint of price controls, price floors and ceilings have been studied by Isaac and Plott (1981) and Smith and Williams (1981). They find that non-binding price controls affect the competitive equilibrium in the double auction

\footnotetext{
${ }^{5}$ We restrict our attention to the winner's curse in Vesteg et al. (2009), who find that the EMP prevents the winner's curse and that the effect is magnified as the number of bidders increases.

${ }^{6}$ Although Dasgupta and Spulber (1990) consider flexible quantity instead of quality in their context, their quality context can be read as quality in our context.

${ }^{7}$ We explicitly introduce the quality of goods in the procurement auction model of Akai et al. (2009a). They find that an FPA without any regulation induces low-quality goods because of the producer's corner-cutting.
} 
experiment. Coursey and Smith (1983) observe the same result in the posted offer market, and Gode and Sunder (2004) present a simple dynamic model with "zero-intelligence" traders to explain this discrepancy.

The paper is organized as follows. Section 2 develops the theoretical model and hypotheses. Section 3 details the experimental design and procedures. Section 4 analyzes the results, and Section 5 contains the conclusion and discussion.

\section{THEORETICAL MODEL AND HYPOTHESIS}

\subsection{THEORETICAL MODEL}

A rule of the FPA with EMP is simply described as follows. Consider that $n$ producers who join this procurement auction. Let $\bar{p}$ be the reservation price determined by a government in advance. Denote producer $i$ 's bid by $b_{i} \in[0, \bar{p}]$, and let this bid function be continuous. A bid profile is $n$-tuple $b=\left(b_{1}, \ldots, b_{n}\right) \in[0, \bar{p}]^{n}$. Given a bid profile $b=\left(b_{1}, \ldots, b_{n}\right)$, denote the first lowest bid by $b^{1}$, the second lowest bid by $b^{2}$, and so on. Given a bid profile $b, 2 \leq m<n$, and $k \in(0,1)$, denote the average bid $a_{m}(b)=\left[b^{1}+\cdots+b^{m}\right] / m$ of the $m$ lowest bids and the minimum price $d(b)=k \cdot a_{m}(b)^{8}$. When a bid profile is $b$, the winner is a producer whose bid is the lowest between $d(b)$ and $\bar{p}$ inclusively, and the winning bid is his/her bid. In case of a tie, such producers win with equal probability.

Procurement auctions for Japanese local governments are held with the same sets of producers who work in the same cities or prefectures. Since wages and rental costs do not generally vary in local areas and a reference book for estimating public constructions is freely available, we assume that every producer has an identical cost $c$ to produce a homogenous good, and the cost is common knowledge among producers ${ }^{9}$. The winning bid in the Nash equilibrium is described in Proposition 1 below, with the proof in Appendix.

PROPOSITION 1. If a bid profile $b$ is a Nash equilibrium, the winning bid coincides with the cost.

In the following example, we divide the Nash equilibria of the FPA with EMP into two cases in order to compare it with the Nash equilibria of the standard FPA that does not have any minimum prices. In Case I, we show the Nash equilibria such that all bids are not less than the cost, that is, $b_{i} \geq c$, for every $i$. This condition is satisfied if the bid profile is a Nash equilibrium in the standard FPA because any producer bidding less than the cost obtains negative payoffs. In Case II, we show the Nash equilibria such that some bids are less than the cost, that is, $b_{i}<c$, for some $i$. Although there is no Nash equilibrium that satisfies this condition in the standard FPA, there are many Nash equilibria that satisfy this condition in the FPA with EMP as described in the example below.

EXAMPLE 1.Let $n=5, k=0.8, m=3, \bar{p}=243$, and $c=97$.

\footnotetext{
${ }^{8}$ In Akai et al. (2009b), we classify the EMP into four types: (i) $k=1$ and $m<n$, (ii) $k=1$ and $m=n$, (iii) $k<1$ and $m<n$, and (iv) $k<1$ and $m=n$. If the cost is identical, Type (iii) of the EMP that we introduce in this paper is the most efficient for the governments and taxpayers to minimize their expenditures.

${ }^{9}$ In this environment, auction is playing fair institution as authorities justify that they do not choose a contractor arbitrarily.
} 
Case I: Nash equilibria such that $b_{i} \geq c$, for every $i$. Consider a bid profile $b=(97,97$, $130,150,160)$. The minimum price is $d(b)=0.8 \cdot(97+97+130) / 3=86.4$, and the winner is one of the producers bidding 97 . If one of the producers bidding 97 raises his/her bid to 130 , then since the minimum price becomes $d(b)=0.8 \cdot(130+97+130) / 3=95.2$ and still remains less than 97 , he/she cannot exclude the other producer bidding 97 . If a producer raises his/her bid to 150 , then since the minimum price becomes $d(b)=0.8 \cdot(150+97+130) / 3=100.5$ and still remains less than 130, he/she cannot exclude the producers bidding less than 130 . A producer cannot affect the minimum price by raising his/her bid to a price more than 150 . If the producer bidding 130 raises his/her bid to 150 , then since the minimum price becomes $d(b)=0.8 \cdot(97+97+150) / 3=91.7$ and still remains less than 97, he/she cannot exclude the producers bidding 97 . In this bid profile, nobody has an incentive to raise the bid and exclude others. Hence, this bid profile is a Nash equilibrium, and the winning bid coincides with the cost of 97.

Next, consider a bid profile $b=(97,97,130,220,230)$. Since $b^{4}=220$ is much higher than $b^{3}=130$, the producer bidding $b^{3}=130$ can exclude the producers bidding 97 by raising his/her bid to $b^{4}=220$. Thus, this bid profile is not a Nash equilibrium. In this auction institution, since $b^{4}$ is the same as the price ceiling for producers bidding less than $b^{4}, b^{4}$ should not be so high that the producers bidding prices less than $b^{4}$ cannot exclude others if a bid profile is a Nash equilibrium.

Case II: Nash equilibria such that $b_{i}<c$, for some $i$. Consider a bid profile $b=(1,97$, $97,150,200)$. The minimum price is $d(b)=0.8 \cdot(1+97+97) / 3=52$, and the winner is one of the producers bidding 97 . If the producer bidding 1 raises his/her bid to 97 , then since his/her payoffs still remain 0 , he/she does not have an incentive to deviate from this bid profile. If a producer raises his/her bid to 150 , then since the minimum price becomes $d(b)=0.8 \cdot(150+$ $97+97) / 3=91.7$ and still remains less than 97 , he/she cannot exclude the producers bidding 97. If the producer bidding 97 raises his/her bid to 150 , then since the minimum price becomes $d(b)=0.8 \cdot(1+97+150) / 3=66.1$ and still remains less than 97 , he/she cannot exclude the other producers bidding 97 . Thus, nobody can affect the minimum price if the producer raises his/her bid more than 150 . Hence, this bid profile is a Nash equilibrium. Similarly, there are many Nash equilibria such that some bids are less than the cost.

Although the EMP expands the Nash equilibria of the standard FPA, winning bids coincide with the cost. That is, the governments and taxpayers can minimize their expenditures throughout this auction institution. Based on the discussion above, we propose hypotheses in the experimental parameter values.

\subsection{HYPOTHESES}

In the experiment, we set the minimum price as $0.8 \times$ average of the lowest 5 bids of 10 producers $(k=0.8, m=5 \text {, and } n=10)^{10}$. We allow the subjects playing the roles of producers to bid only nonnegative integers. To evaluate the performance of the EMP, we compare the winning bids with those of the standard FPA in the identical cost condition and the different cost condition.

First, we propose hypotheses in the identical cost condition. In the identical cost condition, we set every producer's cost as $97(c=97)$. By Proposition 1, the winning bid coincides with

\footnotetext{
${ }^{10}$ This is the first rule employed by the Japanese local governments.
} 
the cost of 97 . Notice that since bids are only integers, a bid profile $b_{1}=\cdots=b_{10}=98$ is also a Nash equilibrium. Therefore, we obtain the following hypothesis.

HYPOTHESIS 1. In the identical cost condition, the winning bid is 97 or 98 .

In the standard FPA, the winning bid also coincides with the cost of 97. Additionally, since bids are only integers, a bid profile $b_{1}=\cdots=b_{10}=98$ is also a Nash equilibrium. Therefore, we obtain the following hypothesis.

HYPOTHESIS 2. In the identical cost condition, the winning bids in the FPA with EMP coincide with the ones in the standard FPA.

Next, we consider the winning bids in the different cost condition. Here, we consider the situation that some big nationwide companies newly join procurement auctions for local governments and they have the power to cut wages and rental costs much more than small localized companies do. We introduce this situation into the laboratory and set producer $i$ 's cost as 97 $\left(c_{i}=97, i=2,5,8\right)$ and producer $j$ 's cost as $150\left(c_{j}=150, j \neq i\right)^{11}$.

Since there are many Nash equilibria in the different cost condition, it is complicated to describe all of them. First, we analyze the winning bid in the Nash equilibrium in Proposition 2 below, with proofs in Appendix. Next, we present an example of the Nash equilibrium.

PROPOSITION 2. Let $c_{1} \leq c_{2} \leq \cdots \leq c_{n}$. If a bid profile $b$ is a Nash equilibrium, the winning bid coincides with the lowest $\operatorname{cost} c_{1}$.

PROPOSITION 3. In the different cost condition, there is no Case I pure Nash equilibrium such that $b_{i} \geq c_{i}$, for every $i$.

The proof of Proposition 3 is provided in supplementary materials. To explain the above proposition intuitively, consider a bid profile $b$ such that every producer whose cost is 97 bids 97 and every producer whose cost is 150 bids 150 . If the producer bidding 97 raises his/her bid to 149 , he/she can pull the minimum price above 97 and be the winner. Therefore, the producers whose costs are 97 have the incentives to raise their bids more than 97 not to be excluded. However, they also keep incentives to reduce their bids to win because there are three producers whose costs are 97 . Hence, they trade off raising and reducing their bids. Thus, there is no Case I pure Nash equilibrium such that every producer bids a price more than or equal to the cost. There are only Case II pure Nash equilibria such that $b_{i}<c_{i}$, for some $i$ in the example below.

EXAMPLE 2. Case II: Nash equilibria such that $b_{i}<c$, for some $i$. Consider a bid profile $b$ such that producers 2,5 , and 8 whose costs are 97 bid 97 , producer 1 whose cost is 150 bids 1 , and the remaining producers whose costs are 150 bid 150 , that is, $b=(1,97,150,150,97,150$, $150,97,150,150)$. In this bid profile, the minimum price is $0.8 \cdot(97+97+97+1+150) / 5=$ 70.7 , and the winner is one of the producers bidding 97 . Since nobody can pull the minimum price above 97, this bid profile is a Nash equilibrium. Similarly, there are many Case II Nash equilibria such that some bids are extremely low.

Notice that since bids are only integers in the experiment, there are Nash equilibria such that the wining bid is 98 . For example, a bid profile $b$ such that producers 2,5 , and 8 whose costs

\footnotetext{
${ }^{11}$ Dufwenberg and Gneezy (2000) find that price competition works well when the number of competitors is three. We follow their idea and allocate the lower cost to three producers.
} 
are 97 bid 98, producer 1 whose cost is 150 bids 1 , and the remaining producers whose costs are 150 bid 150 , that is, $b=(1,98,150,150,98,150,150,98,150,150)$ is a Nash equilibrium ${ }^{12}$. Therefore, we obtain the following hypothesis.

HYPOTHESIS 3. In the different cost condition, the winning bid is 97 or 98 .

In the standard FPA, the winning bid also coincides with the lowest cost of 97. Additionally, since bids are only integers, a bid profile such that producers 2,5 , and 8 bid $98\left(b_{2}=b_{5}=b_{8}=\right.$ 98) and the others bid prices more than 98 is also a Nash equilibrium. Therefore, we obtain the following hypothesis.

HYPOTHESIS 4. In the different cost condition, the winning bids in the FPA with EMP coincide with the ones in the standard FPA.

In the different cost condition, although the Nash equilibria in the FPA with EMP are different from those in the standard FPA, the winning bids are same. From the above hypotheses, there is no difference in the winning bids between the FPA with EMP and the standard FPA in the both cost conditions.

\section{EXPERIMENTAL DESIGN AND PROCEDURES}

\subsection{DESIGN}

Each session proceeded through a sequence of 10 procurement periods and comprised 10 producers who had the same homogenous good ${ }^{13}$. Each subject bid only one selling price per period, and the experimenter bought only one unit of good per period with the reservation price of 243 points of experimental cash. The winner produced a good and earned profits equal to selling price minus cost; other producers did not produce a good and earned zero profits for that period $^{14}$.

Our experiment features three treatment variables - minimum prices, production costs, and the information of subjects' identifications and bids. The minimum prices of our most interest have two conditions - the no-minimum price condition and the EMP condition. In the nominimum price condition, we employed the standard FPA that does not have any minimum prices. In this condition, the winner was the producer whose bid was the lowest among bids

\footnotetext{
${ }^{12}$ Since bids are only integers in the experiment, there are several nonessential Nash equilibria. For example, consider a bid profile $b$ such that producer 2 bids 120, producer 5 bids 130, producer 8 bids 145, producer 1 bids 97, producer 3 bids 121, and the remaining producers bid 145, that is, $b=$ $(97,120,121,145,130,145,145,145,145,145)$. The minimum price is $d(b)=0.8 \cdot(97+120+121+130+$ $145) / 5=98.0$, and the winner is the producer bidding 121. If the producer bidding 97 raises his/her bid to 120 and wins, since his/her cost is 150 , he/she obtains negative payoffs. If the producer bidding 121 reduces his/her bid to 120 and wins, since his/her cost is 150 , he/she obtains negative payoffs. If the producer bidding 130 reduces his/her bid to 120 , since the minimum price $d(b)=(97+120+121+120+145) / 5=120.6$, he/she cannot be the winner. Thus, nobody has an incentive to change the bid, such that this bid profile is a Nash equilibrium. However, essentially, the winning bid coincides with the lowest cost of 97 in the Nash equilibrium.

${ }^{13}$ In Japan, the EMP is often employed when the number of bidders is more than 10. Producers who join the procurement auction with the EMP award a contract roughly once a year. To capture this situation, we conduct an experiment such that a subject wins once with equal probability in the identical cost condition.

${ }^{14}$ We used the term selling price instead of bid and avoided terms such as winners and winning bids in the instructions.
} 
not more than the reservation price, and the winning bid was his/her bid. In case of a tie, such producers won with equal probability. This was the benchmark control condition.

In the EMP condition, we employed the FPA with EMP. The EMP was $80 \%$ of the average of the five lowest bids among ten producers. The winner was the producer whose bid was the lowest between the reservation price and EMP inclusively, and the winning bid was his/her bid. In case of a tie, such producers won with equal probability.

The production costs have two conditions - the identical cost condition and the different cost condition. In the identical cost condition, we announced that the production costs for all producers were 97 points. In the different cost condition, we announced that the production costs for three producers with identification numbers 2, 5, and 8 were 97 points and those of the remaining producers were 150 points. In each condition, subjects were randomly assigned one of the identification numbers and they remained in the same role throughout the session.

The information of subjects' identifications and bids has two conditions - the disclosure condition and the nondisclosure condition. In the procurement auctions for Japanese local governments, producers work in a limited area and are well acquainted with each other. We designed our experiments to assess this environment in the disclosure condition. To this end, in the disclosure condition, at the beginning of the session, we wrote the seating chart of all the producers on a whiteboard in order for the subjects to know which producer had which seat ${ }^{15}$.

After the winner was decided, we clearly announced each bid, in addition to writing it on each seat of the seating chart ${ }^{16}$. After writing all the bids, in the no-minimum price condition, the winning bid, winner's identification number, and winner's profits were displayed on each subject's screen. In the EMP condition, the winning bid, winner's identification number, the average of the five lowest bids, the minimum price, and winner's profits were displayed on each subject's screen.

Since we examined the effect of information of subjects' identifications and bids, we did not disclose the seating chart and all bids in the nondisclosure condition. After the winner was decided, the same type of information provided in the disclosure condition was displayed on each subject's screen.

We used a full factorial design with 2 minimum price conditions $\times 2$ production cost conditions $\times 2$ information conditions of subjects' identifications and bids. Table 2 summarizes our eight cells. Each cell included two sessions. The $\mathrm{N}$ and $\mathrm{E}$ prefix in the session name indicate the no-minimum price condition and the EMP condition, respectively. The -I- and -D- in the middle of the session name indicate the identical cost condition and the different cost condition, respectively. The $-\mathrm{D}$ - and $-\mathrm{N}$ - suffix indicate the disclosure condition and the nondisclosure condition, respectively.

Table 2 is around here

\subsection{Procedures}

The experiments were conducted in the PC laboratory of the Institute of Social and Economic Research at Osaka University. A computerized interface was programmed with the software z-Tree (Fischbacher 2007). Subjects included undergraduate and graduate students of Osaka

\footnotetext{
${ }^{15}$ In our laboratory, the subjects sitting at the rear can see the backs of the subjects sitting ahead of them.

${ }^{16}$ In Japan, some local governments that employ the EMP disclose all bids along with the companies' names.
} 
University ${ }^{17}$. They were invited to sign up at designated websites by flyers posted around the campus and e-mail solicitations sent to students who had signed up for other experiments before. No one participated in more than one session.

Upon arrival, the subjects sat at separate computer terminals, and no communication was permitted throughout the session. The instructions and PC operation manuals are provided in the supplementary materials. Subjects listened to prerecorded instructions, while they followed along on their own copies. Next, they privately read questions and answers about the instructions in 10 minutes to confirm the rules of the experiment ${ }^{18}$. Next, they listened to prerecorded PC operation manuals, while they followed along on their own copies.

After the above procedures were completed, the producers' identification numbers 1 to 10 were determined by a lottery, and each subject received a record sheet. We then provided 10 minutes for subjects to consider the strategy of subsequent auctions.

Then, period 1 began. All the subjects entered their selling price in the computer and their record sheets within three minutes; this was done in each period. As soon as all the subjects bid, the auction was automatically closed and the winner was decided even if three minutes had not elapsed.

In the disclosure condition, we called each bid with an identification number and wrote it on each seat of the seating chart on the whiteboard. In the nondisclosure condition, we did not announce this information. In the no-minimum price condition, subjects entered the winning bid, winner's identification number, and their own profits in their record sheets. In the endogenous minimum price condition, subjects entered the winning bid, winner's identification number, the average of the five lowest bids, the minimum price, and their own profits, in their record sheets.

After period 10 was completed, the record sheets were collected, and their total profits were calculated. Subjects were paid their experimental points in cash under the conversion rate of 1 point equal to 30 yen $(29 \text { cents })^{19}$. All the sessions lasted for approximately 1.5 hours, and the earnings of the subjects ranged from 900 yen $(\$ 8.57)$ to 5,070 yen $(\$ 48.29)$, with a mean of approximately 1,710 yen $(\$ 16.29)$.

\section{RESULTS}

We divide the results into two subsections. Section 4.1 presents the results of the identical cost condition, and Section 4.2 presents the results of the different cost condition. We provide graphs and raw data of the entire experiment in the supplementary materials.

\footnotetext{
${ }^{17}$ Subjects were a mixture of economics majors and noneconomics majors.

${ }^{18}$ Subjects sometimes ask about the detailed strategy of experiments, which might result in a bias in their decision making in the subsequent auction periods. Since we prohibited any questions and excluded any biases, we prepared questions and answers about instructions and distributed them to each subject.

${ }^{19}$ In cells N-I-N and E-I-N, although the conversion rate of 1 point was 30 yen (29 cents), we did not inform the subjects about it. We announced that their initial experimental points were zero and that the higher their experimental points, the more will be their earnings from the experiments. We ensured minimum payments even if the final experimental points were less than or equal to zero in the questions and answers. The minimum payment was 1500 yen $(\$ 14.28)$, which was equal to 50 points $\times 30$ yen $(29$ cents $)$.
} 


\subsection{THE IDENTICAL COST CONDITION}

First, we test Hypothesis 1. Figure 1a presents the average winning bids in cell N-I-D and the average winning bids and the EMP in cell E-I-D. The horizontal axis represents the number of periods and the vertical axis the price. The average winning bids in cells N-I-D and E-I-D are very close to the theoretical prediction of 97 or 98 . The median of the pooled winning bids across the sessions is 98 in cells N-I-D and E-I-D ${ }^{20,21}$. Wilcoxon signed-rank tests do not reject the null hypothesis that the median of the pooled winning bids across the sessions coincides with the theoretical prediction of 98 in cells N-I-D and E-I-D (two-tailed p-values are 1.00 and 0.453 , respectively $)^{22}$.

Figure 1 is around here

Figure $1 \mathrm{~b}$ presents the average winning bids in cell N-I-N and the average winning bids and the EMP in cell E-I-N. The average winning bids in cells N-I-N and E-I-N are very close to the theoretical prediction of 97 or 98 , except in the last period in cell N-I-N. The median of the pooled winning bids across the sessions is 97 in cells N-I-N and E-I-N ${ }^{23}$. Wilcoxon signed-rank tests do not reject the null hypothesis that the median of the pooled winning bids across the sessions coincides with the theoretical prediction of 97 in cells N-I-N and E-I-N (two-tailed pvalues are 1.00 and 0.146 , respectively). These results support Hypothesis 1 . Hence, we obtain the following result.

RESULT 1. In the identical cost condition, the winning bids in the FPA with EMP and those in the standard FPA coincide with the theoretical prediction in both the information conditions.

Next, we test Hypothesis 2. The distributions of the average winning bid in cell N-I-N (N-ID) appear to be similar to those in cell E-I-N (E-I-D). Wilcoxon rank sum tests do not reject the null hypothesis of no difference in the medians of the pooled winning bids across the sessions between cells N-I-D and E-I-D (two-tailed p-value $=0.264$ ) and do not reject the null hypothesis of no difference in the medians of the pooled winning bids across the sessions between cells N-I-N and E-I-N (two-tailed p-value = 0.209). These results support Hypothesis 2. Hence, we obtain the following result.

RESULT 2. In the identical cost condition, the winning bids of the FPA with EMP coincide with those of the standard FPA in both the information conditions.

Next, we focus on the information effect of subjects' identifications and bids within the same auction institution. Wilcoxon rank sum tests do not reject the null hypothesis of no difference

\footnotetext{
${ }^{20}$ Throughout this section, we pool data across two sessions to increase the sample size to 20 , which is sufficient to conduct nonparametric tests. We also report the statistical results, comparing the distribution between two sessions in each cell in each footnote.

${ }^{21}$ The Wilcoxon rank sum tests do not reject the null hypothesis of no differences in the distributions between sessions in the cells N-I-D and E-I-D (two-tailed p-values are 0.69 and 0.15 , respectively).

${ }^{22}$ Although the observations are not independent across the periods within a session, we use Wilcoxon signedrank tests to aid the reader's interpretation of comparing with the theoretical prediction throughout this section.

${ }^{23}$ The Wilcoxon rank sum tests do not reject the null hypothesis of no difference in the distribution between sessions in cell N-I-N (two-tailed p-value is 0.69 ) but reject it in cell E-I-N (two-tailed p-value is 0.04).
} 
in the medians of the pooled winning bids across the sessions between cells E-I-N and E-I-D (two-tailed $\mathrm{p}$-value $=0.128$ ) but reject the null hypothesis of no difference in the medians of the pooled winning bids across the sessions between cells N-I-N and N-I-D (two-tailed p-value $=$ 0.002). Hence, we obtain the following result.

RESULT 3. In the identical cost condition, the winning bids of the FPA with EMP in the disclosure condition coincide with those in the nondisclosure condition. However, the winning bids of the standard FPA in the disclosure condition are slightly higher than those in the nondisclosure condition.

Dufwenberg and Gneezy (2002) find, in their FPA experiment, that although winning bids converge towards the theoretical prediction when they disclose only winning bids, winning bids diverge from the theoretical prediction when they disclose losing bids. In contrast, the winning bids of our standard FPA coincide with the theoretical prediction, and the differences of winning bids between the two information conditions are very small.

The slight difference in the nondisclosure condition seems to be due to the different information of payment schemes. In cells N-I-N and E-I-N, we did not provide a formula to calculate cash rewards from experimental points. Some subjects tended to misunderstand their rewards would be higher when they sold a good than when they did not sell it if their profits were negative. This misunderstanding motivates some subjects to bid prices lower than or equal to the cost of 97 to win.

To avoid the aforementioned misunderstanding, we provide a formula to calculate their rewards in cells N-I-D and E-I-D. It was easier for subjects to understand that negative payoffs would reduce their rewards, so they tried to bid prices higher than the cost of 97 to earn positive profits.

Since the number of bids less than or equal to 97 in cell N-I-N is more than that in cell N-I$\mathrm{D}$, the different information about payment schemes seems to induce the difference of winning bids between these cells. However, we do not observe these differences between cells E-I-N and E-I-D. Although more experimental work is needed to obtain precise results, the information of subjects' identifications and bids does not have a critical impact on the winning bids in either auction institution.

The above results show that both auction institutions achieve the same winning bids. Next, we shift our focus from price competition to evaluating the performance of EMP in relation to the other reason why Japanese local governments employ the EMP, as described below.

Japanese local governments traditionally set the minimum price at $80-90 \%$ of the reservation price, which is generally estimated as the standard cost set by the governments. They believe that the minimum price should be a benchmark of the quality of public works ${ }^{24}$. Many Japanese local governments announce the reservation price and/or the minimum price in order to achieve transparency and fairness ${ }^{25}$. This pre-announcement, however, creates the problem of all producers who join this auction bidding the minimum price; the winner is selected by lottery regardless of the real costs and qualities ${ }^{26}$. Even when they pre-announce only the reser-

\footnotetext{
${ }^{24}$ In Japan, the law of local government procurement requires reservation prices in order to avoid a situation in which contract prices exceed the budget.

${ }^{25}$ According to the Ministry of Land, Infrastructure, Transport and Tourism's survey (2007) of 1,874 local governments, $64 \%$ of all local governments announced the reservation price in advance, and $65 \%$ of all local governments employed the minimum price. Of these governments, $20 \%$ announced the minimum price in advance.

${ }^{26}$ According to the Ministry of Land, Infrastructure, Transport and Tourism's survey (2006) of 1,826 local governments that employed the minimum price from April 2003 to July 2004 (this frequency is about $56 \%$ of the
} 
vation price, the same problem occurs because producers can easily estimate the minimum price from the traditional reservation price. Thus, not only in order to exclude abnormally low bids but also to avoid selecting the winner by lottery, they have started to employ the EMP.

To test this performance, we compare the frequency of deciding winners by lottery between the FPA with EMP and the standard FPA. The numbers pertaining to deciding the winner by lottery are 13 and 10 in cells E-I-D and N-I-D, respectively. The proportion test does not reject the null hypothesis of no difference in the frequencies of deciding the winner by lottery between cells E-I-D and N-I-D (two-tailed p-value $=0.337$ ). On the other hand, the numbers pertaining to deciding the winner by lottery are 12 and 8 in cells E-I-N and N-I-N, respectively. The proportion test does not reject the null hypothesis of no difference in the frequencies of deciding the winner by lottery between cells E-I-N and N-I-N (two-tailed p-value $=0.205$ ). Hence, we obtain the following result.

RESULT 4. In the identical cost condition, there is no difference in the frequency of deciding winners by lottery between the FPA with EMP and the standard FPA in both information conditions.

As a result, the winners were decided by lottery in roughly half the periods in both auctions. In the identical cost condition, the EMP does not affect the winning bids or the frequency of deciding the winner by lottery. Next, we evaluate the effect of EMP in the different cost condition.

\subsection{THE DIFFERENT COST CONDITION}

First, we test Hypothesis 3. Figure 2a presents the average winning bids in cell N-D-D and the average winning bids and the EMP in cell E-D-D. The winning bids in cell E-D-D depart from the theoretical predictions of 97 and 98 . The medians of the pooled winning bids across the sessions in cells N-D-D and E-D-D are 100 and 119.5, respectively ${ }^{27}$. Wilcoxon signed-rank tests reject the null hypothesis that the medians of the pooled winning bids across the sessions coincides with 97 or 98 at the $1 \%$ significance level in both the cells.

Figure $2 \mathrm{~b}$ presents the average winning bids in cell N-D-N and the average winning bids and the EMP in cell E-D-N. Both the winning bids tend to decrease toward the theoretical prediction as the periods proceed. The medians of the pooled winning bids across the sessions in cells ND-N and E-D-N are 106 and 102, respectively ${ }^{28}$. Wilcoxon signed-rank tests reject the null hypothesis that the median of the pooled winning bids across the sessions coincides with 97 or 98 at the $1 \%$ significance level in each cell.

Figure 2 is around here

\footnotetext{
3,228 local governments existing at the time), 145 local governments decided the winner by lottery during that period. This frequency is $61 \%$ of the 236 local governments that announced the minimum price in advance.

${ }^{27}$ The Wilcoxon rank sum tests reject the null hypothesis of no difference in the distribution between sessions in cell N-D-N (two-tailed p-value is 0.01), but do not reject it in cell E-D-N (two-tailed p-value is 0.61).

${ }^{28}$ The Wilcoxon rank sum tests reject the null hypothesis of no difference in the distribution between sessions in cell N-D-D (two-tailed p-value is 0.01), but do not reject it in cell E-D-N (two-tailed p-value is 0.79).
} 
The winning bids in cells N-D-N and E-D-N, however, appear to converge towards the theoretical prediction of 98; those in cells N-D-D and E-D-D do not. We test whether the winning bids converge towards the theoretical prediction. We define that the winning bids converge towards the theoretical prediction if the slopes of the OLS regression of winning bids on the number of periods are significantly negative and the winning bids in the last five periods coincide with the theoretical prediction.

Table 3 is around here

Table 3 presents the results of the OLS regression of the pooled winning bids across two sessions on the number of periods in cells N-D-D, E-D-D, N-D-N, and E-D-N:

$$
\text { Winning bids }=a+b \cdot \text { Period }+\varepsilon
$$

In cells N-D-D and E-D-D, however, the slopes are not significant at the 5\% level, and the joint F-statistic tests of slopes and constants are not significant at the 5\% level. The medians of the pooled winning bids in the last five periods across the sessions are 100 and 116 in cells N-D-D and E-D-D, respectively. Wilcoxon signed-rank tests reject the null hypothesis that the medians of the pooled winning bids in the last five periods across the sessions coincides with 98 in cells N-D-D and E-D-D (two-tailed p-values are 0.015 and 0.002 , respectively). These results do not support Hypothesis 3, that is, winning bids do not converge towards 98 .

In cells N-D-N and E-D-N, the slopes are negative and the constants are positive. They are significant at the $1 \%$ level. The joint F-statistic tests of slopes and constants are also significant at the $1 \%$ level. The medians of the pooled winning bids in the last five periods across the sessions are 100.5 and 98 in cells N-D-N and E-D-N, respectively. Wilcoxon signed-rank tests do not reject the null hypothesis that the medians of the pooled winning bids in the last five periods across the sessions coincide with 98 in cells N-D-N and E-D-N (two-tailed p-values are 0.062 and 1.000 , respectively). These results support that winning bids converge towards 98. Therefore, Hypothesis 3 is supported in the nondisclosure condition. Hence, we obtain the following result.

RESULT 5. In the different cost condition, the winning bids in the FPA with EMP and the standard FPA do not converge towards the theoretical prediction in the disclosure condition, but converge towards the theoretical prediction in the nondisclosure condition.

Next, we test Hypothesis 4. The average winning bids in cell E-D-N are higher than those in cell N-D-N, except in Period 9. Wilcoxon rank sum tests reject the null hypothesis of no difference in the medians of the winning bids between cells N-D-D and E-D-D (two-tailed pvalue $=0.000)$. On the other hand, the distribution of the average winning bids in cell E-D-D appears to be similar to that in cell N-D-D. Wilcoxon rank sum tests do not reject the null hypothesis of no difference in the medians of the winning bids between cells N-D-N and E$\mathrm{D}-\mathrm{N}$ (two-tailed p-value $=0.463$ ). Therefore, Hypothesis 4 is supported in the nondisclosure condition but not in the disclosure condition. Hence, we obtain the following result. 
RESULT 6. In the different cost condition, the winning bids of the FPA with EMP are higher than those of the standard FPA in the disclosure condition. However, the winning bids of the FPA with EMP coincide with those of the standard FPA in the nondisclosure condition.

The above result implies that the information of subjects' identifications and bids affects the winning bids. Next, we focus on the effect of this information within the same auction institutions. Wilcoxon rank sum tests reject the null hypothesis of no difference in the medians of the pooled winning bids between cells E-D-N and E-D-D (z-value $=3.88$, two-tailed p-value $=0.000$ ), but do not reject the null hypothesis of no difference in the medians of the pooled winning bids between cells N-D-N and N-D-D (z-value $=-1.28$, two-tailed p-value $=0.199$ ). Thus, we obtain the following result.

RESULT 7. In the different cost condition, the winning bids of the FPA with EMP in the disclosure condition are higher than those in the nondisclosure condition. However, the winning bids of the standard FPA in the nondisclosure condition coincide with those in the disclosure condition.

Next, we compare E-D-N and E-D-D and consider why winning bids in cell E-D-N diverge from the theoretical prediction. As we described in Section 2.2, in the different cost condition, the FPA with EMP has many Case II Nash equilibria such that $b_{i}<c_{i}$, for some $i$, but it does not have any Case I pure Nash equilibrium such that $b_{i} \geq c_{i}$, for any $i$. The FPA with EMP approximately achieves Case II Nash equilibria in the nondisclosure condition in the last five periods but not in the disclosure condition in all the periods.

There are many 1 point bids in cell E-D-N, whereas there are three 1 point bids in cell E-DD. Specifically, in cell E-D-N, Producers 7, 9, and 10 in Session 1, and Producer 4 in Session 2 repeatedly bid 1. The EMPs fell below 80 from Period 5, except in Period 10 in Session 1. In cell E-D-D, however, nobody repeated a bidding of 1 from Period 5, and the EMPs were higher than 105, except in Periods 6, 9, and 10 in Session 1.

According to the questionnaire sheets that we distributed after the experiment, Producers 4 and 10 who repeated a bidding of 1 in cell E-D-N changed their strategies during the course of the experiment to reduce the payoffs of the producers whose costs are 97 by bidding extremely low prices. Their motivation seems to be similar to the spiteful strategies defined by Cason et al. (2004) in the non-excludable public goods experiments. They define a strategy as being a spiteful strategy "if he/she selects a strategy reducing both his/her own payoff and the other subject's payoff in comparison to the payoffs when he/she takes an own payoff-maximizing strategy, given an expected strategy of the other subject" 29 .

We expand this definition to include the meaning of expected payoffs and apply it to the incentive of repeated bidding of 1 for the producer whose cost is 150 . Since bidding a price lower than the cost has the risk of negative payoffs, the expected payoffs of the producer whose cost is 150 are smaller when he/she bids 1 than when he/she bids 151, given any bid profiles. The producer's strategy of bidding 1, however, reduces not only his/her own expected payoffs but also those of the producer whose cost is 97.

Given bidding prices of more than 150 from producers whose costs are 150, if producers whose costs are 97 bid prices between 97 and 150, they can win, and the winner's payoff ranges from $1 / 3$ to $52^{30}$. On the other hand, given a bidding price of 1 from producers whose costs

\footnotetext{
${ }^{29}$ Cason et al. (2004), p. 89, l.4-6.

${ }^{30}$ The minimum expected payoff is $1 / 3$ if three producers, whose costs are 97 , bid 98 ; the maximum expected payoff is 52 if only one producer, whose cost is 97 , bids 149 and wins.
} 
are 150, the expected payoff-maximizing strategy of producers whose costs are 97 is bidding 98 , and their expected payoffs are $1 / 3$ at the most. Thus, a bidding price of 1 from producers whose costs are 150 is a spiteful strategy in view of expected payoffs. Thus, the nondisclosure condition leads to a spiteful strategy, which motivates producers whose costs are 97 to bid prices close to their costs so that the winning bids are close to their costs.

The disclosure condition, however, reduces the spiteful strategy of bidding 1 which leads to Case II Nash equilibria. If producers whose costs are 97 do not assume extremely low bids and assume that all producers bid prices higher than their costs, they have the incentive to bid prices more than their cost not to be excluded by the EMP. Specifically, consider a situation in which a producer whose cost is 97 bids 150 and producers whose costs are 150 bid 151. In this situation, if the remaining producers whose costs are 97 bid 98, they are excluded by the EMP of 103. Thus, since producers whose costs are 97 bid prices more than their costs not to be excluded, the winning bids in cell E-D-N diverge from their costs.

Next, we consider the market efficiency defined by the total surplus of the government and producers. In view of the market efficiency, the most efficient case is that the producer whose cost is 97 produces the goods and sells them to the government. In cell E-D-D, Producer 10 whose cost is 150 won with her bid of 151 in Period 10 of Session 1, and Producer 7 whose cost is 150 won at her bid of 155 in Period 8 of Session 2. These observations imply that the FPA with EMP has a risk of losing market efficiency when production costs are different if governments disclose producers' identifications and bids. We compare the frequency of achieving the most efficient case between cells N-D-D and E-D-D. The proportion test does not reject the null hypothesis of no difference in the frequencies of achieving the most efficient case between cells N-D-D and E-D-D (two-tailed p-value = 0.146). Hence, we obtain the following result.

RESULT 8. In the different cost condition, there is no difference in the market efficiencies between the FPA with EMP and the standard FPA.

In both the auction institutions, producers whose costs are 97 mostly win. Next, we compare the frequencies of deciding winners by lottery between the FPA with EMP and the standard FPA. The numbers pertaining to deciding the winners by lottery are 1 and 2 in cells E-I-D and N-I-D, respectively. The proportion test does not reject the null hypothesis of no difference in the frequencies of deciding the winners by lottery between cells E-D-D and N-D-D (twotailed $\mathrm{p}$-value $=0.548$ ). On the other hand, the numbers pertaining to deciding the winners by lottery are 10 and 2 in cells E-D-N and N-D-N, respectively. The proportion test rejects the null hypothesis of no difference in the frequencies of deciding the winners by lottery between cells E-I-N and N-I-N (two-tailed p-value $=0.005$ ). Hence, we obtain the following result.

RESULT 9. In the different cost condition, there is no difference in the frequencies of deciding the winners by lottery between the FPA with EMP and the standard FPA in the disclosure condition. However, the frequency of the FPA with EMP is higher than that of the standard FPA in the nondisclosure condition.

The frequencies of deciding the winners by lottery in cell E-D-N is high and is the same as those in cells in the identical cost condition. One possible reason why cell E-D-N induces high frequencies is that the bidding price of 1 from producers whose costs are 150 lowers the EMP, which allows producers whose costs are 97 to easily stay close to their costs of 97 relative to the standard FPA. In the standard FPA, since there are only three producers whose costs are 97 and the competition power is weak, they try to bid higher prices than their costs in order to increase 
their profits instead of bidding close to their costs to become the winner. If this interpretation is correct, the existence of the EMP leads to having to decide the winners by lottery. This situation is unexpected for Japanese local governments that wish to prevent deciding winners by lottery.

\section{CONCLUSION AND DISCUSSION}

In this paper, we evaluate the performance of the FPA with EMP relative to the standard FPA which does not have any minimum prices. Theoretically, in the identical cost condition, the EMP expands the Nash equilibria of the FPA, and the FPA comes to include the Nash equilibria such that $b_{i}<c$, for some $i$. In the different cost condition, the EMP changes the Nash equilibria of the FPA, and the FPA comes to hold only the Nash equilibria such that $b_{i}<c$, for some $i$. However, in both production cost conditions, since the EMP does not affect the winning bids of the FPA in the Nash equilibria, the winning bids consistent with their costs which are the most efficient outcomes for the government and taxpayers to minimize their expenditures.

In the experiment, in the identical cost condition, the winning bids in both the FPA with EMP and the standard FPA are consistent with the cost; these values are not significantly different regardless of the information of subjects' identifications and bids. Further, the EMP does not affect the frequency of deciding the winners by lottery.

In the different cost condition, when the information of subjects' identifications and bids is disclosed, the winning bids of the FPA with EMP diverge from the lowest cost and are significantly higher than those of the standard FPA. However, when the information of subjects' identifications and bids are not disclosed, the winning bids of the FPA with EMP and the standard FPA converge towards the theoretical predictions, and these values are not significantly different. In latter case, the EMP increases the frequency of deciding the winners by lottery. The EMP, however, does not affect market efficiency defined by the total surplus of the government and producers.

In the different cost condition, the nondisclosure of subjects' identifications and bids leads to bidding 1 point to reduce the payoffs of producers with the lowest cost, using the spiteful strategy. This behavior lowers the EMP to below the lowest cost. Thus, producers with the lowest cost bid prices close to their costs to win and winning bids converge toward the lowest cost.

The disclosure condition, however, does not lead to bidding 1 point as the spiteful strategy, and the EMP becomes higher than the lowest cost. Thus, producers with the lowest costs raise their bids not to be excluded by the EMP; the winning bids diverge from the lowest cost. Since the disclosure of subjects' identifications and bids reduces the bidding of 1 as the spiteful strategy, it seems to be easier for subjects to adopt the spiteful strategy when their identifications and actions are hidden. In socio-psychology, Yamagishi $(1988 \mathrm{a} ; 1988 \mathrm{~b})$ find that the mutual monitoring and sanctioning remove the free riding in Japan. In our different cost condition, the mutual monitoring removes spiteful strategy, which makes the winning bids diverge from the lowest cost.

These results suggest that auctioneers need to pay attention to the information control of producers' identifications and bids when they employ the EMP. Isaac and Walker (1985) and Dufwenberg and Gneezy (2002) also caution about the disclosure of information concerning losing bids because this information reduces (increases) the auctioneer's revenues (losses). Additionally, our results are similar to those of Isaac and Plott (1981), Smith and Williams (1981), Coursey and Smith (1983), and Gode and Sunder (2004), who reveal that non-binding price 
controls affect trading prices in the competitive market. Although the EMP does not affect the winning bids of the FPA in theory, it affects them under the specific information control experiment.

Although more experimental work is needed to obtain precise results, if we can say that concealing the identifications and actions of subjects induces a spiteful strategy, which in turn induces the efficient outcome for the government and taxpayers, auction authorities have to take steps to protect companies' identifications in the procurement procedures. To this end, sealed bids by postal mail or via the Internet, recently employed by some Japanese local governments, are useful in concealing who the bidder is. The EMP, however, does not have a critical impact on the prevention of deciding winners by lottery, as expected by Japanese local governments.

Although our result calls the government's attention to the EMP's risk of inducing higher winning bids and a higher frequency of deciding winners by lottery, our study cannot deny the need of the EMP in procurement procedures because we restrict our attention to homogenous goods. As we mentioned in the introduction, auctioneers began using the EMP to prevent buying abnormally low-quality goods. Next, we expand on Akai et al. (2009a), who explicitly introduce quality into the procurement auction model, and evaluate whether the EMP prevents the purchase of low quality goods and whether it increases social welfare in various environments.

Additionally, bid-rigging is a substantive problem, as Isaac and Walker (1985), Saijo et al. (1996), and Kawagoe (2003) study. Since bidders can manipulate the EMP, this method is often criticized for its tendency to collude in manipulating the EMP and excluding their rivals. A simple way to manipulate the EMP is to create a dummy company. In fact, these problems are concerned when Japanese local governments began employing the EMP. If auction authorities follow our suggestions and do not disclose information about bidder's identifications and bids, they can promote collusion or the creation of dummy companies and make it difficult to state that the auction institution is transparent and fair for public procurement. Our final goal is to assess whether the EMP prevents the purchase of abnormally low-quality goods at a fair price even if we allow bidders to conspire.

\section{ACKNOWLEDGEMENTS}

This research was partially support by the Japanese Ministry of Education, Culture, Sports, Science and Technology (the COE program of Behavioral Macrodynamics based on Surveys and Experiments; the Grant-in-Aid for Scientific Research on Priority Areas). We wish to acknowledge the helpful comments of Toshiji Kawagoe, Akihiko Matsui, Charles Noussaire, Vesteg Robert, Junyi Shen, and Thakehiko Yamato and participants at meetings of the Asia Pacific Economic Science Association and Japanese Economic Association and conferences of the Experimental Social Sciences in Japan. We also thank Keiko Aoki, Atsushi Hirata, and Tsuyoshi Nihonsugi for assistance conducting the experiment.

\section{References}

[1] Akai, K., Saijo, T., Serizawa, S., 2009a. Auctions for Public Construction with Cornercutting. ISER Discussion Papare No. 740.

[2] Akai, K., Saijo, T., Serizawa, S., 2009b. An Experimental Study of Japanese Procurement Auctions with Endogenous Minimum Prices. ISER Discussion Papare No. 743. 
[3] Brosig, J., Reiß, J. P., 2007. Entry decisions and bidding behavior in sequential first-price procurement auctions: An experimental study Games and Economic Behavior 58, 50-74.

[4] Calveras, A., Ganuza, J., Hauk, E., 2004. Wild Bids. Gambling for resurrection in procurement contracts. Journal of Regulatory Economics 26, 41-68.

[5] Che, Y. K, 1993. Design competition through multidimensional auctions. The RAND Journal of Economics 24, 668-680.

[6] Coursey, D., Smith, V.L., 1983. Price controls in a posted offer market. American Economic Review 73, 218-221.

[7] Cox, J. C., Isaac, R. M., Cech, P., Conn, D., 1996. Moral hazard and adverse selection in procurement contracting. Games and Economic Behavior 17, 147-176.

[8] Dasgupta, S., Spulber, D., 1990. Managing Procurement Auctions. Information Economics and Policy 4, 5-29.

[9] Decarolis, F., 2009. When the highest bidder loses the auction: theory and evidence from public procurement. Working papaer of Banca D'Italia 717.

[10] Dufwenberg, M., Gneezy, U., 2000. Price competition and market concentration: an experimental study. International Journal of Industrial Organization 18, 7-22.

[11] Dufwenberg, M., Gneezy, U., 2002. Information disclosure in auctions: an experiment. Journal of Economic Behavior and Organization 48, 431-444.

[12] Fischbacher, U., 2007. z-Tree: Zurich Toolbox for ready-made economic experiments, Experimental Economics 10, 171-178.

[13] Gode, D. K., Sunder, S., 2004. Double auction dynamics: structural effects of non-binding price controls. Journal of Economic Dynamics \& Control 28, 1707-1731.

[14] Isaac, R.M., Plott, C.R., 1981. Price controls and the behavior of auction markets: An experimental examination. The American Economic Review 71, 448-459.

[15] Isaac, R. M., Walker, M. J. 1985. Information and conspiracy in sealed bid auctions. Journal of Economic Behavior and Organization 6, 139-159.

[16] Kagel, H. J, Levin, D., 2002. Common Value Auctions and the Winner's Curse. Princeton University Press.

[17] Kawagoe, T., 2003. "An Experimental Examination of Random-cut Method in Designated Competitive Bidding" (in Japanese), RIETI Discussion Paper Series 03-J-010. http://www.rieti.go.jp/jp/publications/dp/03j010.pdf.

[18] Manelli, A. M., Vincent, D. R., 1995. Optimal procurement mechanisms. Econometrica 63, 591-620.

[19] Naegelen, F., 2002. Implementing optimal procurement auctions with exogenous quality.Review of Economic Design 7, 135-153. 
[20] Ohno, T., Harada, Y., 2006. A Comparison of Tendering and Contracting Systems for Public Works between Japan, the United States and EU Countries. Government Auditing Review 14, 49-71.

[21] Saijo, T., Une, M., Yamaguchi, T., 1996. "Dango" experiments. Journal of the Japanese and International Economies 10, 1-11.

[22] Sinclair-Desgagne B., 1990. On the regulation of procurement bids. Economics Letters $33,229-232$.

[23] Smith, V. L., Williams, A.W., 1981. On nonbinding price controls in a competitive market. The American Economic Review 71, 467-474.

[24] Veszteg, F. R., Akai, K., Saijo, T., Serizawa, S., 2009. Auctions with Endogenous Price Ceiling: Theoretical and Experimental Results. ISER Discussion Papare No. 747.

[25] Von Ungern-Sternberg, T., 1994. Quality incentives in auctions for construction contracts. International Journal of Industrial Organization 12, 89-104.

[26] Yamagishi, T., 1988a. The Provision of a Sanctioning System in the United States and Japan. Social Psychology Quarterly 51, 265-271.

[27] Yamagishi, T., 1988b. Exit from the Group as an Individualistic Solution to the Free Rider Problem in the United States and Japan. Journal of Experimental Social Psychology 24, $530-542$.

\section{WEB REFERENCES}

[1] The European Commission, 1999. Prevention, detection and elimination of abnormally low tenders in the European construction industry. URL: http://ec.europa.eu/enterprise/construction/alo/altfin.htm.

[2] The Ministry of Internal Affaires and Communications in Japan, 2007. URL: http://www.soumu.go.jp/s-news/2007/pdf/070223_6_bs.pdf (in Japanese).

[3] The Ministry of Land, Infrastructure, Transport and Tourism, 2006. URL: http://www.mlit.go.jp/singikai/kensetsugyou/tekiseika/050513/06.pdf.

[4] The Ministry of Land, Infrastructure, Transport and Tourism, 2007. URL: http://www.mlit.go.jp/kisha/kisha07/01/011219_html (in Japanese).

[5] The East Japan Construction Surety Co.,Ltd. URL: http://www.ejcs.co.jp/ (in Japanese).

[6] The Hokkaido Construction Surety Co.,Ltd.: URL: http://www2.hokkaido-cs.co.jp/kdc_hkd/index.html (in Japanese).

[7] The West Japan Construction Surety Co.,Ltd. URL: http://www.wjcs.net/index.html (in Japanese). 


\section{Appendix}

\section{PROOF OF PROPOSITION 1.}

Step 1: More than one producers bid $b^{*}$. Suppose that only one producer bids $b^{*}$. This winner can raise her bid to the price slightly less than the second lowest bid, $b^{*}+\varepsilon<b^{2}$, and increase her payoffs. This is a contradiction.

Step 2: $b^{*}=c$. Suppose $b^{*}>c$. Case 1: $d(b)<b^{*}$. The producer bidding $b^{*}$ has an incentive to reduce her bid to $b^{*}-\varepsilon$ and increase her payoffs. This is a contradiction. Case2: $d(b)=b^{*}$. If the producer bidding $b^{*}$ raises her bid to the price slightly less than the second highest bid, $b^{2}-\varepsilon$, then since she can pull the minimum price above $b^{*}$ and exclude other producers bidding $b^{*}$, she can increase her payoffs. This is a contradiction.

\section{PROOF OF PROPOSITION 2.}

Step 1: More than one producers bid $b^{*}$. Suppose that only one producer bids $b^{*}$. This winner can raise her bid to the price slightly less than the second lowest bid, $b^{*}+\varepsilon<b^{2}$, and increase her payoffs. This is a contradiction.

Step 2: The winner is a producer whose cost is $c_{1}$. Suppose that the winner is a producer whose cost is more than or equal to $c_{3}$. Since $b^{*}>c_{3}$, the producer whose $\operatorname{cost}$ is $c_{1}$ can raise her bid to $b^{*}$ and increase her payoffs. This is a contradiction.

Step 3: $c_{1} \leq b^{*}<c_{3}$. Suppose $b^{*}<c_{1}$. Since the winner is the producer whose cost is $c_{1}$ and her payoffs are less than zero, she has an incentive to raise her bid to $c_{1}$ and increase her payoffs. This is a contradiction. Suppose $b^{*} \geq c_{3}$. Case 1: $d(b)<b^{*}$. The producer whose cost is $c_{1}$ has an incentive to reduce her bid to $b^{*}-\varepsilon$, and increase her payoffs. This is a contradiction. Case2: $d(b)=b^{*}$. If the producer whose cost is $c_{1}$ raises her bid to the price slightly less than the second highest bid, $b^{2}-\varepsilon$, then since she can pull the minimum price above $b^{*}$ and exclude other producers bidding $b^{*}$, she can increase her payoffs. This is a contradiction.

Step 4: $b^{*}=c_{1}$. Suppose $b^{*}>c_{1}$. Case 1: $d(b)<b^{*}$. The producer whose cost is $c_{1}$ has an incentive to reduce her bid to $b^{*}-\varepsilon$ and increase her payoffs. This is a contradiction. Case2: $d(b)=b^{*}$. If the producer whose cost is $c_{1}$ raises her bid to the price slightly less than the second highest bid, $b^{2}-\varepsilon$, then since she can pull the minimum price above $b^{*}$ and exclude other producers bidding $b^{*}$, she can increase her payoffs. This is a contradiction. 
Table 1. An example of the EMP

\begin{tabular}{lccccccccc}
\hline Ranking of bids & 1 & 2 & 3 & 4 & 5 & 6 & 7 & The EMP & The winning bid \\
\hline bids (before) & $\$ 100$ & $\$ 105$ & $\$ 130$ & $\$ 150$ & $\$ 160$ & $\$ 180$ & $\$ 200$ & $\$ 103$ & $\$ 105$ \\
bids (after) & $\$ 100$ & $\$ 105$ & $\$ 149$ & $\$ 150$ & $\$ 160$ & $\$ 180$ & $\$ 200$ & $\$ 106$ & $\$ 149$ \\
\hline
\end{tabular}

Table 2. The environment of each cell

\begin{tabular}{lclll}
\hline Cell & $\begin{array}{c}\text { Number of } \\
\text { sessions }\end{array}$ & $\begin{array}{c}\text { Minimum price } \\
\text { conditions }\end{array}$ & $\begin{array}{c}\text { Production } \\
\text { cost conditions }\end{array}$ & $\begin{array}{l}\text { Information conditions of } \\
\text { subjects' identifications and bids }\end{array}$ \\
\hline N-I-D & 2 & No & Identical & Disclosure \\
E-I-D & 2 & Endogenous & Identical & Disclosure \\
N-I-N & 2 & No & Identical & Nondisclosure \\
E-I-N & 2 & Endogenous & Identical & Nondisclosure \\
N-D-D & 2 & No & Different & Disclosure \\
E-D-D & 2 & Endogenous & Different & Disclosure \\
N-D-N & 2 & No & Different & Nondisclosure \\
E-D-N & 2 & Endogenous & Different & Nondisclosure \\
\hline
\end{tabular}

Table 3. OLS regressions of winning bids on periods

\begin{tabular}{lllll}
\hline Cell & N-D-D & E-D-D & N-D-N & E-D-N \\
\hline a & $102.60 * * *(5.60)$ & $131.77^{* * *}(5.49)$ & $127.83^{* * *}(3.81)$ & $131.20^{* * *}(4.66)$ \\
b & $0.40(0.90)$ & $-1.54 *(0.88)$ & $-3.23^{* * *}(0.61)$ & $-4.05 * * *(0.75)$ \\
F-statistic & 0.20 & $3.03^{*}$ & $27.67^{* * *}$ & $29.18^{* * * *}$ \\
adjusted R & -0.04 & 0.10 & 0.58 & 0.60 \\
No. of Obs. & 20 & 20 & 20 & 20 \\
\hline
\end{tabular}

Note: Standard errors are in parentheses. ${ }^{*}, * *$, and $* * *$ denote significance at the $10 \%, 5 \%$, and $1 \%$ levels, respectively. 
Figure 1. Average winning bids and EMPs in the identical cost condition

Figure 1a

Figure 1b

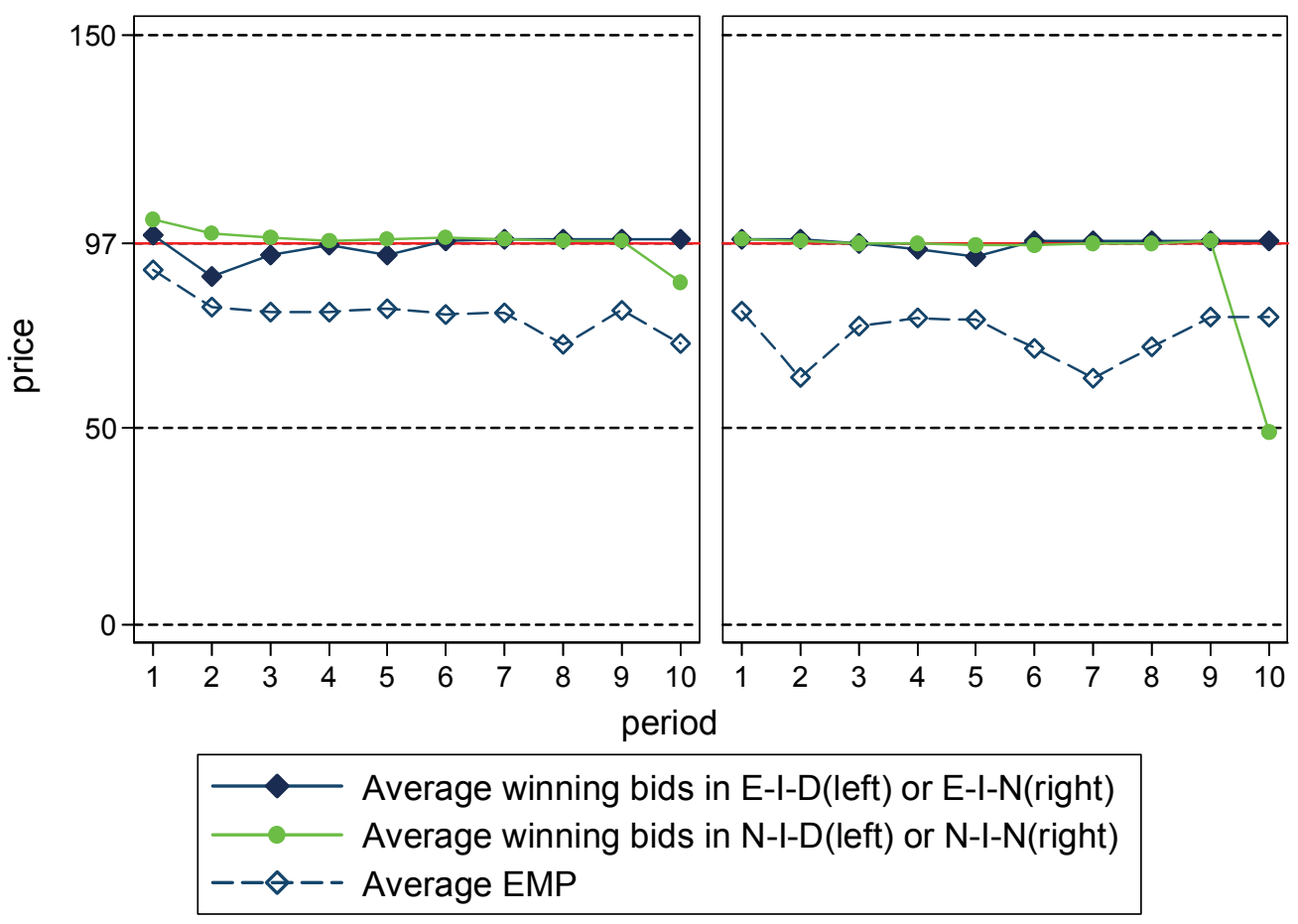

Figure 2. Average winning bids and EMPs in the different cost condition

Figure $2 \mathrm{a}$

Figure $2 b$

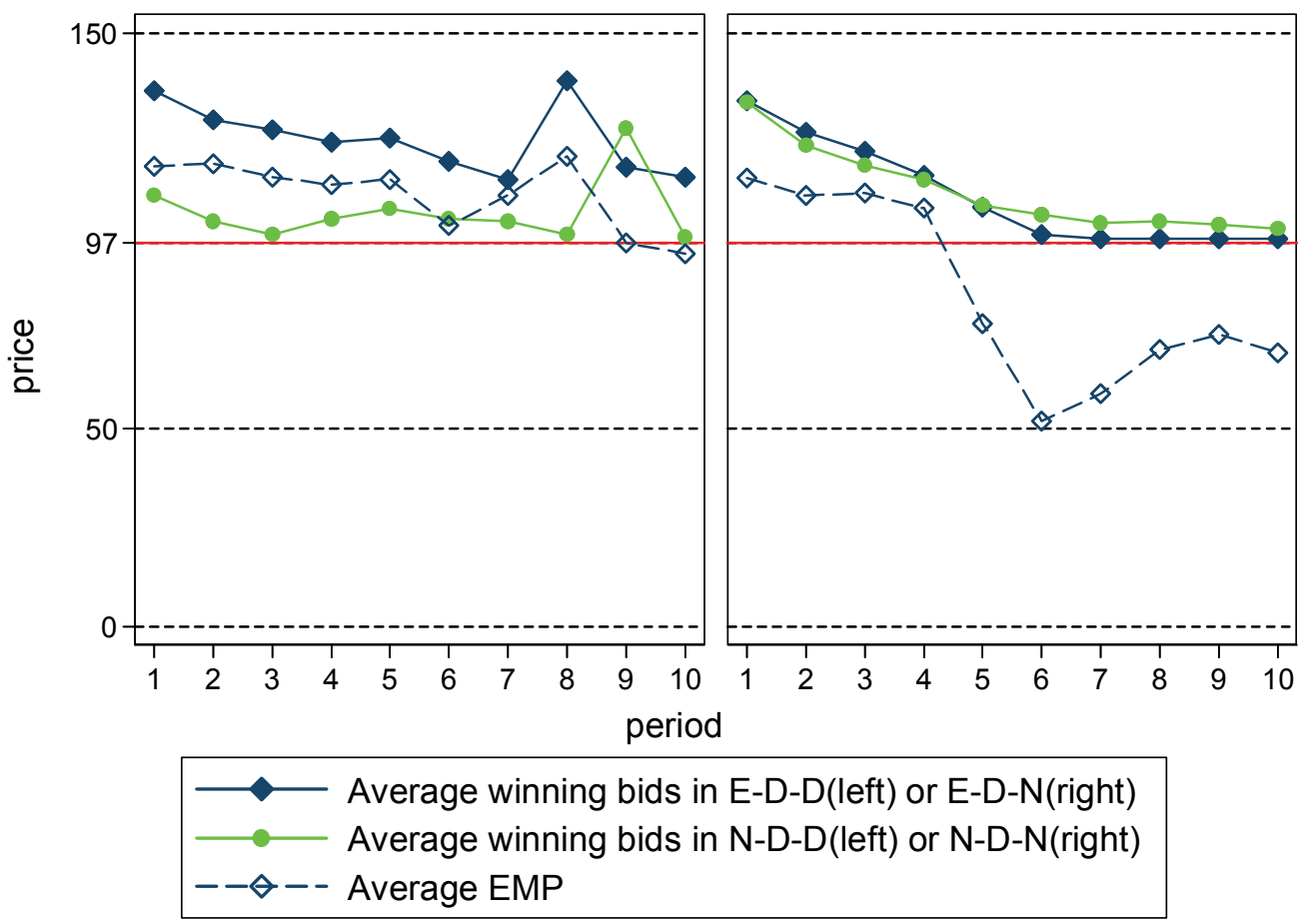




\section{Supplementary Material for \\ "An Experimental Study of Procurement Auctions with Endogenous Minimum Prices"}

This supplementary material has four sections. Section 1 provides the proof of Proposition 3. Section 2 contains instructions and PC operation manuals. Sections 3 and 4 provide graphs and raw data of the entire experiments, respectively.

\section{Proof of Proposition 3}

Here, we show that there are no Case I pure Nash equilibrium in our setting. First we describe four lemmas and use them for the proof of Proposition 3.

In the following model, when a bid profile is $b$, producer $i$ 's probability $X_{i}(b)$ of selling the good is : $X_{i}(b)=0$ if $b_{i}>\min \left\{b_{j}: b_{j} \geq d(b)\right\}$, and $X_{i}(b)=1 / n^{\prime}$ if $b_{i}=\min \left\{b_{j}: b_{j} \geq\right.$ $d(b)\}$, where $n^{\prime}$ is the number of bids of $\arg \min \left\{b_{j}: b_{j} \geq d(b)\right\}$. When a bid profile is $b$, producer $i$ 's (expected) payoff is $u_{i}(b)=\left(b_{i}-c_{i}\right) \cdot X_{i}(b)$, where $c_{i}$ is producer $i$ 's cost for the good considered. Following the experiment, we assume that bids are nonnegative integers and that producer 1 has the lowest cost, producer 2 has the second lowest cost, and so on, that is, $c_{1} \leq c_{2} \leq \cdots \leq c_{n}$. Given a bid profile $b$, let $b^{*}(b)$ be the winning bid of $b$, that is, $b^{*}(b)=\min \left\{b_{i}: i \in N\right.$ and $\left.b_{i} \geq d(b)\right\}$.

Lemma 1: In a Nash equilibrium $b$ such that $b_{i} \geq c_{i}$ for every $i$, no bid is excluded by $d(b)$, that is, $b^{1}(b) \geq d(b)$.

Proof. Suppose that there is a bid $b_{i}$ excluded by $d(b)$, that is, $b_{i}<d(b)$. Note that $u_{i}(b)=0$. Let $\widehat{b}_{i}=b^{*}(b)$. If producer $i$ can be a winner by bidding $\widehat{b}_{i}$, that is, $\widehat{b}_{i}=\min \left\{b_{j}: j \in N\right.$ and $\left.b_{j} \geq d\left(\widehat{b}_{i}, b_{-i}\right)\right\}$, then since $\widehat{b}_{i}=b^{*}(b) \geq d(b)>b_{i}>c_{i}$, and $X_{i}\left(\widehat{b}_{i}, b_{-i}\right)>0$, it follows that $u_{i}\left(\widehat{b}_{i}, b_{-i}\right)=\left(\widehat{b}_{i}-c_{i}\right) \cdot X_{i}\left(\widehat{b}_{i}, b_{-i}\right)>0=u_{i}(b)$. This is a contradiction to Nash equilibrium. Let $\widetilde{b}_{i}=b^{m}(b)$, that is, $\widetilde{b}_{i}$ is equal to the $m$-th lowest bid among $\left\{b_{1}, \ldots, b_{n}\right\}$. Note that $\widetilde{b}_{i}>d\left(\widetilde{b}_{i}, b_{-i}\right) \geq d\left(\widehat{b}_{i}, b_{-i}\right) \geq d(b)$. Thus, if producer $i$ cannot be a winner by bidding $\widehat{b}_{i}$, then producer $i$ can be a winner by bidding some $\bar{b}_{i} \in\left[b^{*}(b), b^{m}(b)\right]$, and similarly he can obtain a positive $u_{i}\left(\bar{b}_{i}, b_{-i}\right)$. This is also a contradiction to Nash equilibrium.

QED

REMARK: In the Nash equilibrium $b$ such that $b_{i} \geq c_{i}$ for all $i, b^{*}(b)=\min \left\{b_{i}: i \in N\right\}$.

Lemma 2: Let $b_{i} \geq c_{i}$ for all $i$. In the Nash equilibrium $b$, for all $i \in N$, if $b^{*}(b)>c_{i}$, $b_{i}=b^{*}(b)$.

Proof. Suppose that $b^{*}(b)>c_{i}$, and $b_{i} \neq b^{*}(b)$ for some $i \in N$. By Lemma 1 , for all $i \in N, b_{i} \geq b^{*}(b) \geq d(b)$. Thus, $b_{i}>b^{*}(b)>c_{i}$. By $b_{i}>b^{*}(b), u_{i}(b)=0$. Let $\widehat{b}_{i}=b^{*}(b)$. Note that $d\left(\widehat{b}_{i}, b_{-i}\right) \leq d(b) \leq b^{*}(b)=\widehat{b}_{i}$. By Lemma 1 , for all $j \in N, b_{j} \geq b^{*}(b)=\widehat{b}_{i}$. Thus, producer $i$ can be a winner by bidding $\widehat{b}_{i}$, that is, $\widehat{b}_{i}=\min \left\{b_{j}: j \in N\right.$ and $\left.b_{j} \geq d\left(\widehat{b}_{j}, b_{-1}\right)\right\}$. Since $\widehat{b}_{i}=b^{*}(b)>c_{i}$, and $X_{i}\left(\widehat{b}_{i}, b_{-i}\right)>0$, it follows that $u_{i}\left(\widehat{b}_{i}, b_{-i}\right)=\left(\widehat{b}_{i}-c_{i}\right) \cdot X_{i}\left(\widehat{b}_{i}, b_{-i}\right)>$ $0=u_{i}(b)$. This is a contradiction to Nash equilibrium. Thus, for all $i \in N$, if $b^{*}(b)>c_{i}$, $b_{i}=b^{*}(b)$.

QED

LEMma 3: In the Nash equilibrium $b$ such that $b_{i} \geq c_{i}$ for all $i$, if $b^{*}(b)>\max \left\{c_{1}+\right.$ $\left.2, c_{2}\right\}$, then $d(b) \in\left(b^{*}(b)-1, b^{*}(b)\right]$. 
Proof. Suppose $b^{*}(b)>\max \left\{c_{1}+2, c_{2}\right\}$ and $d(b) \leq b^{*}(b)-1$. Since Lemma 2 implies $b_{1}=b_{2}=b^{*}(b), X_{1}(b) \leq 1 / 2$. Thus, $u_{1}(b)=\left(b_{1}-c_{1}\right) \cdot X_{1}(b) \leq\left(b_{1}-c_{1}\right) / 2$. Note

$$
\begin{aligned}
b^{*}(b)>c_{1}+2 & \Rightarrow 2 \cdot\left\{b^{*}(b)-c_{1}\right\}-2>b^{*}(b)-c_{1} \\
& \Rightarrow\left\{b^{*}(b)-1-c_{1}\right\}>\left(b_{1}-c_{1}\right) / 2 .
\end{aligned}
$$

By bidding $b^{*}(b)-1$, producer 1 can be a single winner and can obtain the payoff $\left(b^{*}(b)-\right.$ $\left.1-c_{1}\right)>\left(b_{1}-c_{1}\right) / 2=u_{1}(b)$. This is a contradiction to Nash equilibrium. Thus, $d(b) \in$ $\left(b^{*}(b)-1, b^{*}(b)\right]$.

QED

Lemma 4: In the Nash equilibrium $b$ such that $b_{i} \geq c_{i}$ for all $i, b^{1}(b)=b^{*}(b) \leq b^{2}(b) \leq$ $b^{*}(b)+1$.

Proof. By Lemma $1, b^{1}(b)=b^{*}(b) \geq d(b)$. By definition, $b^{1}(b) \leq b^{2}(b)$. Thus, we show $b^{2}(b) \leq b^{*}(b)+1$. Suppose $b^{2}(b)>b^{*}(b)+1$. Let $i \in N$ be such that $b_{i}=b^{1}(b)$. Let $\widehat{b}_{i}=b^{*}(b)+1$. Then, $u_{i}\left(\widehat{b}_{i}, u_{-i}\right)=b^{*}(b)+1-c_{i}>b^{*}(b)-c_{i}=u_{i}(b)$. This is a contradiction to Nash equilibrium.

QED

Proposition 3: Let $n=10, m=5, k=4 / 5, c_{1}=c_{2}=c_{3}=97, c_{4}=\cdots=c_{10}=150$. There is no Case I pure Nash equilibrium $b_{i} \geq c_{i}$, for every $i$.

Proof. Suppose there is a Nash equilibrium $b$ such that $b_{i} \geq c_{i}$ for all $i$. Since $b_{i} \geq c_{i}$ for all $i$, it follows that for all $i \in N, c_{i}<b_{i}$ and $c_{i}<b^{i}(b)$. Note that $b^{*}(b) \geq b^{1}(b) \geq$ $c_{1}=98$. We derive a contradiction in each of the following cases.

Case 1. $b^{*}(b) \geq 151 .\left(b^{*}(b) \geq c_{5}+1.\right)$

By Lemma 2 and $b^{*}(b)>c_{5}, b_{1}=\cdots=b_{5}=b^{*}(b)$. Thus, by Lemma $1, b^{1}(b)=\cdots=$ $b^{5}(b)=b^{*}(b)$, and so $d(b)=(4 / 5) \cdot b^{*}(b)$. By Lemma $3,(4 / 5) \cdot b^{*}(b)>b^{*}(b)-1$. This inequality implies $b^{*}(b)<5$. This is a contradiction to $b^{*}(b) \geq 151$.

Case 2. $98 \leq b^{*}(b) \leq 150 .\left(c_{3}+1 \leq b^{*}(b) \leq c_{4}.\right)$

By Lemma 2 and $b^{*}(b)>c_{3}, b_{1}=b_{2}=b_{3}=b^{*}(b)$. Thus, by Lemma $1, b^{1}(b)=b^{2}(b)=$ $b^{3}(b)=b^{*}(b)$, and so $d(b)=(4 / 5) \cdot\left[3 \cdot b^{*}(b)+b^{4}(b)+b^{5}(b)\right] / 5$. Since $b_{i} \geq c_{i}, b^{4}(b) \geq 151$ and $b^{5}(b) \geq 151$. Note that $u_{3}(b)=\left[b^{*}(b)-97\right] / 3 \leq[150-97] / 3$.

By Lemma $3, b^{*}(b)-1<(4 / 5) \cdot\left[3 \cdot b^{*}(b)+b^{4}(b)+b^{5}(b)\right] / 5$. Thus, $\left[13 \cdot b^{*}(b)-25\right] / 4<$ $b^{4}(b)+b^{5}(b)$. Let $\widehat{b}_{3}=b^{4}(b)$.

We show $d\left(\widehat{b}_{3}, b_{-3}\right)>b^{*}(b)=b_{1}=b_{2}$. Suppose $d\left(\widehat{b}_{3}, b_{-3}\right) \leq b^{*}(b)$. Since $\left[13 \cdot b^{*}(b)-\right.$ $25] / 4<b^{4}(b)+b^{5}(b),\left[13 \cdot b^{*}(b)-25\right] / 4-b^{5}(b)<b^{4}(b)$. Thus,

$$
\begin{aligned}
& b^{*}(b) \\
& \geq d\left(\widehat{b}_{3}, b_{-3}\right) \\
& =\frac{4}{5} \cdot \frac{2 \cdot b^{*}(b)+b^{4}(b)+b^{4}(b)+b^{5}(b)}{5} \\
& =\frac{4}{25} \cdot\left[2 \cdot b^{*}(b)+2 \cdot b^{4}(b)+b^{5}(b)\right] \\
& >\frac{4}{25} \cdot\left[2 \cdot b^{*}(b)+2 \cdot \frac{13 \cdot b^{*}(b)-25}{4}-2 \cdot b^{5}(b)+b^{5}(b)\right] \quad \text { by } b^{4}(b)>\frac{13 \cdot b^{*}(b)-25}{4}-b^{5}(b) \\
& =\frac{1}{25} \cdot\left[8 \cdot b^{*}(b)+2 \cdot\left\{13 \cdot b^{*}(b)-25\right\}-4 \cdot b^{5}(b)\right] \\
& =\frac{1}{25} \cdot\left[34 \cdot b^{*}(b)-50-4 \cdot b^{5}(b)\right] .
\end{aligned}
$$


Therefore,

$$
\begin{aligned}
b^{*}(b) & >\frac{1}{25} \cdot\left[34 \cdot b^{*}(b)-50-4 \cdot b^{5}(b)\right] \\
25 \cdot b^{*}(b) & >34 \cdot b^{*}(b)-50-4 \cdot b^{5}(b) \\
4 \cdot b^{5}(b) & >9 \cdot b^{*}(b)-50 \\
b^{5}(b) & >\left[9 \cdot b^{*}(b)-50\right] / 4 .
\end{aligned}
$$

Let $\widehat{b}_{4}=b_{5}$. Then,

$$
\begin{aligned}
d\left(\widehat{b}_{4}, b_{-4}\right) & =\frac{4}{5} \cdot \frac{3 \cdot b^{*}(b)+2 \cdot b^{5}(b)}{5} \\
& >\frac{4}{25} \cdot\left[3 \cdot b^{*}(b)+2 \cdot \frac{9 \cdot b^{*}(b)-50}{4}\right] \quad \text { by } b^{5}(b)>\frac{9 \cdot b^{*}(b)-50}{4} \\
& =\frac{1}{25} \cdot\left[30 \cdot b^{*}(b)-100\right] .
\end{aligned}
$$

Thus, if $d\left(\widehat{b}_{4}, b_{-4}\right) \leq b^{*}(b)$, then $\frac{1}{25} \cdot\left[30 \cdot b^{*}(b)-100\right]<b^{*}(b)$. This inequality implies $b^{*}(b)<20$. This is a contradiction to $b^{*}(b) \geq 98$. Thus, $d\left(\widehat{b}_{4}, b_{-4}\right)>b^{*}(b)=b_{1}=b_{2}=b_{3}$. Since $d\left(\widehat{b}_{4}, b_{-4}\right) \leq b^{5}(b)=\widehat{b}_{4}, X_{4}\left(\widehat{b}_{4}, b_{-4}\right) \geq 1 / 2$, and so

$$
u_{4}\left(\widehat{b}_{4}, b_{-4}\right) \geq\left[b^{5}(b)-c_{4}\right] / 2 \geq[151-150] / 2>0=u_{3}(b) .
$$

Since $b$ is a Nash equilibrium, this is a contradiction. Therefore, $d\left(\widehat{b}_{3}, b_{-3}\right)>b^{*}(b)=b_{1}=$ $b_{2}$.

Note

$$
\begin{aligned}
d\left(\widehat{b}_{3}, b_{-3}\right) & =\frac{4}{5} \cdot \frac{2 \cdot b^{*}(b)+b^{4}(b)+b^{4}(b)+b^{5}(b)}{5} \\
& =\frac{4}{25} \cdot\left[3 \cdot b^{*}(b)+\left\{b^{4}(b)-b^{*}(b)\right\}+b^{4}(b)+b^{5}(b)\right] \\
& =\frac{4}{25} \cdot\left[3 \cdot b^{*}(b)+b^{4}(b)+b^{5}(b)\right]+\frac{4}{25} \cdot\left\{b^{4}(b)-b^{*}(b)\right\} \\
& =d(b)+\frac{4}{25} \cdot\left\{b^{4}(b)-b^{*}(b)\right\} \\
& \leq b^{*}(b)+\frac{4}{25} \cdot\left\{b^{4}(b)-b^{*}(b)\right\} \\
& <b^{*}(b)+\left\{b^{4}(b)-b^{*}(b)\right\}=b^{4}(b) .
\end{aligned}
$$

Therefore, $d\left(\widehat{b}_{3}, b_{-3}\right) \leq b^{4}(b)=\widehat{b}_{3}$. Thus, $X_{3}\left(\widehat{b}_{3}, b_{-3}\right) \geq 1 / 2$, and so

$$
u_{3}\left(\widehat{b}_{3}, b_{-3}\right) \geq\left[b^{4}(b)-c_{3}\right] / 2 \geq[151-97] / 2>[150-97] / 3 \geq u_{3}(b) .
$$

Since $b$ is a Nash equilibrium, this is a contradiction.. 


\section{Instructions and PC operation manuals}

\section{Instructions (for cell E-I-D)}

In this experiment, every subject makes a decision on selling the goods to the experimenter. Please understand the rules of the experiment well, make an appropriate decision, and earn as much rewards as possible.

\section{Outline of the experiment}

In this experiment, you will be assigned a role of a producer, and sell a "good" to the experimenter. The number of subjects participating in this experiment is 10 people in total. Each subject acts the role of the producer. The computer acts as the experimenter. The experiment will be repeated 10 periods. In each period, the experimenter purchases a good from a producer according to pre-determined certain rules. Following explains the rules of purchasing a good for the experimenter acted by the computer and the role of a producer every subject acts.

\section{The purchasing rules of the experimenter}

First, we explain the purchasing rules of the experimenter acted by the computer. The experimenter purchases one unit of "good" from one of 10 producers according to the rules below. The purchasing rules of the experimenter are as follows.

First of all, the experimenter asks all 10 producers to submit the selling prices for the good through computer display. Money used in this experiment is measured by "point” of a fictitious monetary unit. The experimenter purchases a good at the selling price less than or equal to 243 points. Therefore, the maximum selling price of you as the producer can submit to the experimenter is 243 pt. Note that selling prices you can submit are only integers. You have three minutes to input your selling price on your computer screen. Note that you cannot cancel the selling price once you have submitted it to the experimenter.

Next, the experimenter selects five producers in the order of the lowest selling prices. The experimenter calculates the average selling price of these five producers. Then, this average is multiplied by 0.8 . The experimenter selects one producer whose selling price is the lowest among all the producers who have submitted the selling prices higher than or equal to " $0.8 \times$ (average selling price of lowest five producers)". The experimenter purchases the good from that producer at the selling price he/she has submitted. 
If there are two or more producers who have submitted that price, then the experimenter randomly selects one of them and purchases the goods from that producer.

\section{Roles of producers}

We explain the role of the producer you act. Before the beginning of the experiment, every subject will be assigned to a producer's identification number from 1 to 10 by a lottery. Once you receive a producer's number, that number will not change throughout the experiment.

Each producer can produce one unit of good at "production costs". The production cost of a good are common among all producers and it is $97 \mathrm{pt}$. The quality of the good any producers produce is same.

When a producer is selected by the experimenter, he/she is to produce a good and sell it to the experimenter to get "sales revenues". Since the unit of goods you can sell is one unit, the sales revenue is equal to the selling price to the experimenter, i.e. equal to the purchase price of the experimenter. The difference between the sales revenue and the production cost of the good is a "profit" the producer earns from the production and sales. That is, "profit $=$ purchase price of the experimenter - production cost of the good."

However, producers who do not sell the good to the experimenter do not produce a good. In this case, these producers do not earn sales revenues but have no production cost incurred either, so his/her profit is $0 \mathrm{pt}$.

\section{Purchasing rules of the experimenter and an example of the way to calculate producers' profits}

This section explains the purchasing rules of the experimenter and the example of way to calculate producers' profits by using actual numbers. Although the experimenter do not purchase any goods with the selling price higher than 243 points in the experiment, here we assume that the experimenter can purchase a good at the price higher than 243 points, and explain the example.

For example, producers number 1 to 10 submit the following selling prices respectively as their selling prices: 3000 pt, 4000 pt, 5000 pt, 6000 pt, 7000 pt, 8000 pt, 5000 pt, 3000 pt, 4000 pt and 9000 pt. Five lowest prices are 3000 pt $=3000$ pt $<4000$ $\mathrm{pt}=4000 \mathrm{pt}<5000$ pt. The average of these prices is $(3000+3000+4000+4000+$ $5000) / 5=3800$ pt. Multiplying this with 0.8 , we get $3800 \times 0.8=3040$ pt. All the selling prices equal to or higher than this number are $4000 \mathrm{pt}=4000 \mathrm{pt}<5000 \mathrm{pt}=$ 
5000 pt $<6000$ pt $<7000$ pt $<8000$ pt $<9000$ pt. The lowest price is 4000 pt among them. However, there are two producers who have submitted 4000 pt of selling price. Therefore, one of them will be selected with the probability of $1 / 2$, and that producer sells the good to the experimenter.

At this point, the producer selected by the experimenter is to produce a good at the production cost of $97 \mathrm{pt}$ so that this producer's profit is $4000-97=3903 \mathrm{pt}$. All other producers' profits are $0 \mathrm{pt}$.

Let us repeat that, in the actual experiment, the experimenter purchases the good at the price lower than or equal to 243 pt. Every subject decide what selling price you are to submit to the experimenter, while taking account of what selling prices other producers submit, and try to earn as much rewards as possible.

\section{Completion of the experiment and the calculation of rewards}

Once all the producers submit their selling prices, the experimenter notify all producers from whom the experimenter purchases a good according to the rules as we explained earlier.

The experimenter discloses the following 4 types of information to all producers: "producer's identification number from whom the experimenter purchase a good", "the purchasing price of the experimenter", "average of five lowest selling prices", and " $0.8 \times$ (average of lowest five selling prices)". At this point, the first period finishes. Once the first period finishes, the second period will start with same procedures. At the time 10th period finishes this experiment is completed.

After the end of the experiment, the rewards each subject receives is calculated from total profits of the producer each subject acts. Specifically, the rewards to each subject after the end of the experiment are calculated as the following formula.

Rewards after the end of the experiment $=(50 \mathrm{pt}+$ Gross profit $) \times 30$ Yen

We explain about this formula in detail. At the beginning of the experiment, each subject is given $50 \mathrm{pt}$ only once. Total profits as the sum of the profits of producer you act for 10 periods are added to the 50 pts. However, profits can be minus in the experiment. If you submit the selling price below the production cost and the experimenter purchases the goods at that selling price, your profit will be minus. If the total profits as the sum of profits for 10 periods are minus, it will be subtracted from 50 pts given to you at the beginning of the experiment. Each subject receives the rewards in cash under the conversion rate of $1 \mathrm{pt}=30$ yen. Please try to earn as much rewards as 
possible.

Above is the content of today's experiment. During the experiment, do not talk to others, and follow orders of the experimenter. You make a decision in the experiment by the software that operates on the personal computer assigned to each subject. The attached "PC Operation Manual" describes how to operate the PC. We will explain about this manual after the next reading period of "questions and answers on instructions”.

This part is for the different production cost condition.

\section{Roles of producers}

We explain roles of producers you act. Before the beginning of the experiment, every subject will be assigned to a producer identification number from 1 to 10 by a lottery. Once you receive a producer number, that number will not change throughout the experiment.

Each producer can produce one unit of good at "production cost”. Production costs of a good are in the table below.

\begin{tabular}{|c|c|c|c|c|c|c|c|c|c|c|}
\hline Producer No. & 1 & 2 & 3 & 4 & 5 & 6 & 7 & 8 & 9 & 10 \\
\hline Cost & $150 \mathrm{pt}$ & $97 \mathrm{pt}$ & $150 \mathrm{pt}$ & $150 \mathrm{pt}$ & $97 \mathrm{pt}$ & $150 \mathrm{pt}$ & $150 \mathrm{pt}$ & $97 \mathrm{pt}$ & $150 \mathrm{pt}$ & $150 \mathrm{pt}$ \\
\hline
\end{tabular}

Producer number 1 has the production cost of 150 pt, No. 2 has 97 pt, No. 3 150 pt, No. 4150 pt, No. 597 pt, No. 6150 pt, No. 7150 pt, No. 897 pt, No. 9150 pt, and No. 10150 pt. The quality of goods any producers produce is the same.

When a producer is selected by the experimenter, he/she is to produce a good and sell it to the experimenter to get "sales revenue". Since the unit of goods sold is one unit, the sales revenue is equal to the selling price to the experimenter, i.e. equal to the purchase price of the experimenter. The difference between the sales revenue and the production cost of the good is the "profit" the producer earns from the production and sales. In other words, "profit = purchase price of the experimenter - production cost of the good.”

However, producers who do not sell the good to the experimenter do not produce a good. In this case, these producers do not earn sales revenue but have no production cost incurred either, so his/her profit is $0 \mathrm{pt}$. 


\section{Purchasing rules of the experimenter and an example of the way to calculate producers' profits}

This section explains the purchasing rules of the experimenter and the example of way to calculate producers' profits by using actual numbers. Although the experimenter do not purchase any goods with the selling price higher than 243 points in the experiment, here we allow the experimenter to purchase a good at the price higher than 243 points and explain the example.

For example, producers number 1 to 10 submit the following selling prices respectively as their selling prices: 3000 pt, 4000 pt, 5000 pt, 6000 pt, 7000 pt, 8000 pt, 5000 pt, 3000 pt, 4000 pt and 9000 pt. Five lowest prices are 3000 pt $=3000$ pt $<4000$ $\mathrm{pt}=4000 \mathrm{pt}<5000 \mathrm{pt}$. The average of these prices is $(3000+3000+4000+4000+$ $5000) / 5=3800$ pt. Multiplying this with 0.8 , we get: $3800 \times 0.8=3040$ pt. All the selling prices equal to or higher than this number are $4000 \mathrm{pt}=4000 \mathrm{pt}<5000 \mathrm{pt}=$ 5000 pt $<6000$ pt $<7000$ pt $<8000$ pt $<9000$ pt. The lowest price is 4000 pt among them. However, there are two producers who have submitted 4000 pt of selling price. Therefore, one of them will be selected with the probability of $1 / 2$, and that producer sells the good to the experimenter.

At this point, if the producer with production cost of 97 pt is selected, then he/she produces a good at $97 \mathrm{pt}$, so his/her profit is $4000-97=3903$ pt. If the selected producer has the production cost of $150 \mathrm{pt}$, then he/she manufactures goods at the cost of $150 \mathrm{pt}$, and his/her profit is $4000-150=3850 \mathrm{pt}$. All other producers' profits are 0 pt.

Let us repeat that, in the actual experiment, the experimenter purchases the good at the price lower than or equal to 243 pt. Every subject decide what selling price you are to submit to the experimenter, while taking account of what selling prices other producers submit, and try to earn as much rewards as possible.

This part is for the nondisclosure condition.

\section{Completion of the experiment and the calculation of rewards}

Once all the producers submit their selling prices, the experimenter notify all producers from whom the experimenter purchases a good according to the rules as we explained earlier.

The experimenter discloses the following 4 types of information to all producers: "producer's identification number from whom the experimenter purchase a good”, "the purchasing price of the experimenter", "average of five lowest selling 
prices", and " $0.8 \times$ (average of lowest five selling prices)". At this point, the first period finishes. Once the first period finishes, the second period will start with same procedures. At the time 10th period finishes this experiment is completed.

After the end of the experiment, the rewards each subject receives are calculated from total profits of the producer each subject acts. Specifically, the rewards to each subject after the end of the experiment are calculated as the following formula.

Rewards after the end of the experiment $=(50 \mathrm{pt}+$ Gross profit $) \times 30$ Yen

We explain about this formula in detail. At the beginning of the experiment, each subject is given $50 \mathrm{pt}$ only once. Total profits as the sum of the profits of producer you act for 10 periods are added to the 50 pt. However, profits can be minus in the experiment. If you submit the selling price below the production cost and the experimenter purchases the goods at that selling price, your profit will be minus. If the total profits as the sum of profits for 10 periods are minus, it will be subtracted from 50 pts given to you at the beginning of the experiment. Each subject receives the rewards in cash under the conversion rate of $1 \mathrm{pt}=30$ yen.

The experimenter will not disclose to other subjects whom is assigned to which producer number during and after the experiment. Therefore, try to earn as much rewards as possible without concern for others. Please try to earn as much rewards as possible.

This part is for cells E-I-N and N-I-N.

\section{Completion of the experiment and the calculation of rewards}

After the end of the experiment, the rewards for each subject are calculated from total profits of the producer each subject acts. Although every subject cannot know the formula to calculate the rewards, that formula is common among all subjects and have a feature that greater the total profit of the producer you act the greater the rewards.

At the beginning of the experiment, the profit of each producer is $0 \mathrm{pt}$. If you submit the selling price below the production cost and the experimenter purchases the goods at that selling price, your profit will be minus. Even if the total profits are 0 pt or minus, each subject is guaranteed to receive the minimum rewards. We cannot tell you how much the minimum rewards are. The rewards paid to the subject with the negative total profits are the same regardless of how big the negative profits are. Moreover, the 
subject with the negative total profits and the subject with 0 pt will receive the same minimum rewards.

The experimenter will not disclose to other subjects whom is assigned to which producer number during and after the experiment. Therefore, try to earn as much rewards as possible without concern for others. 


\section{PC operation manuals (for the endogenous minimum price condition)}

In the experiment, each subject sells a good to the experimenter by using the PC assigned to each of them. We explain screens of the software we use in the experiment and how to manipulate it as follows.

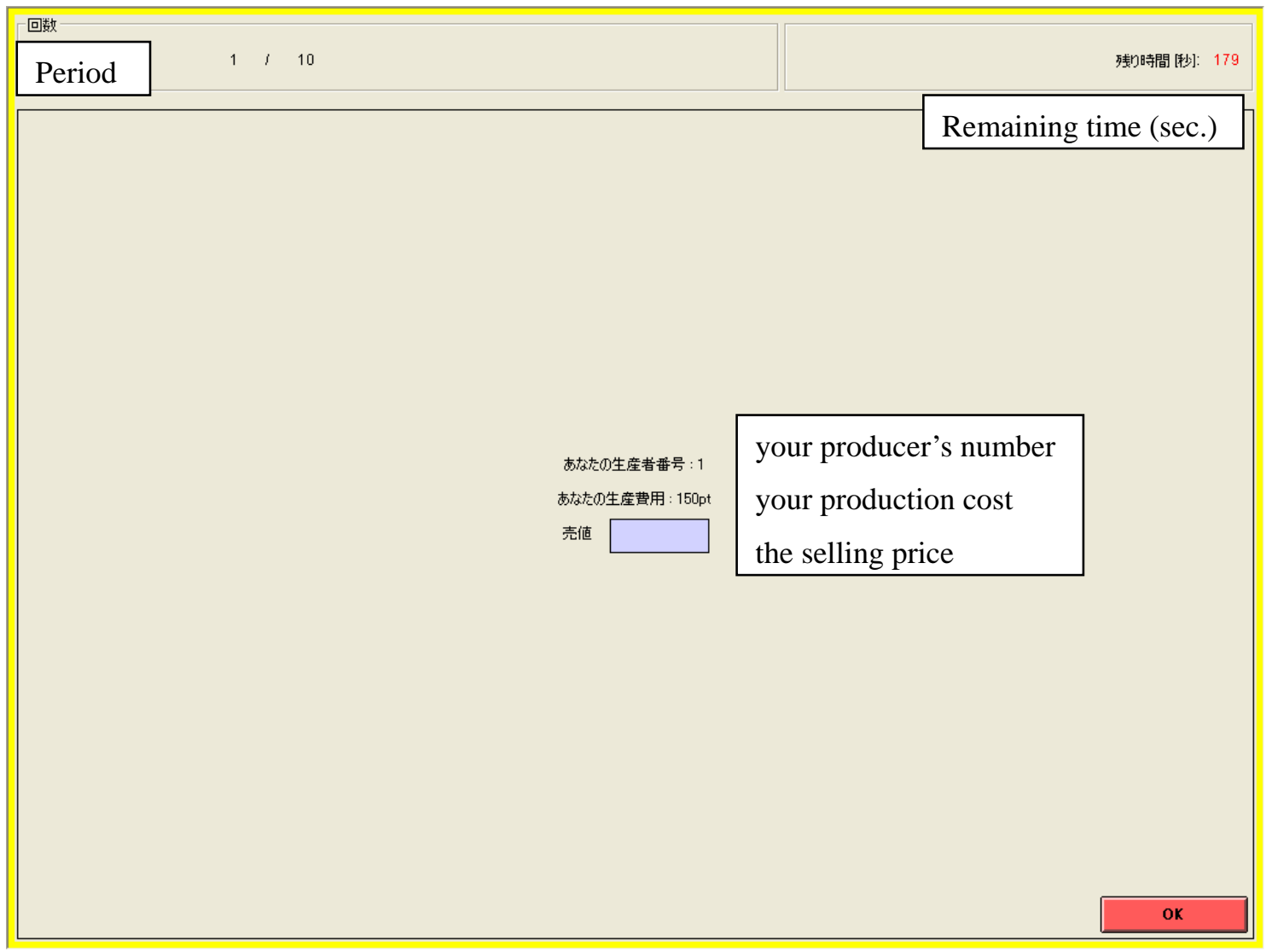

Screen 1

As soon as period 1 starts, the experimenter asks each producer to submit a selling price. Screen 1 is shown in the screen of the PC in front of every subject.

Please see screen 1. In the center of this screen, "your producer's number", "your production cost", and a cell you submit a "selling price" are displayed. In this example, the cell of “your producer's number” displays producer 1. Producer 1's production cost is 150 pt so that the cell of "your production cost" displays 150 pt. Any subjects submit integers between 1 pt and 243 pt (limits included). Every subject inputs the selling price and then writes that selling price in the cell in the record sheet. After you complete writing, click OK button in the upper-right corner of the screen. Note you can neither cancel nor correct once you 
click OK button. Please pay attention about it carefully.

Additionally, "period" in the upper-left corner of the screen displays what period is in the experiment. In screen 1 , it displays " $1 / 10$ " as shown period 1 . "Remaining period" in the upper-right corner of the screen displays how long you have left for submitting a selling price to the experimenter. Any subjects input the selling prices within 3 minutes (180 seconds). You necessarily input the selling price. The experimenter encourages subjects who do not input yet after the remaining time elapse 0 to input the selling price. Notice once all subjects click OK button, the experimenter start purchasing procedures even though 3 minutes do not elapse.

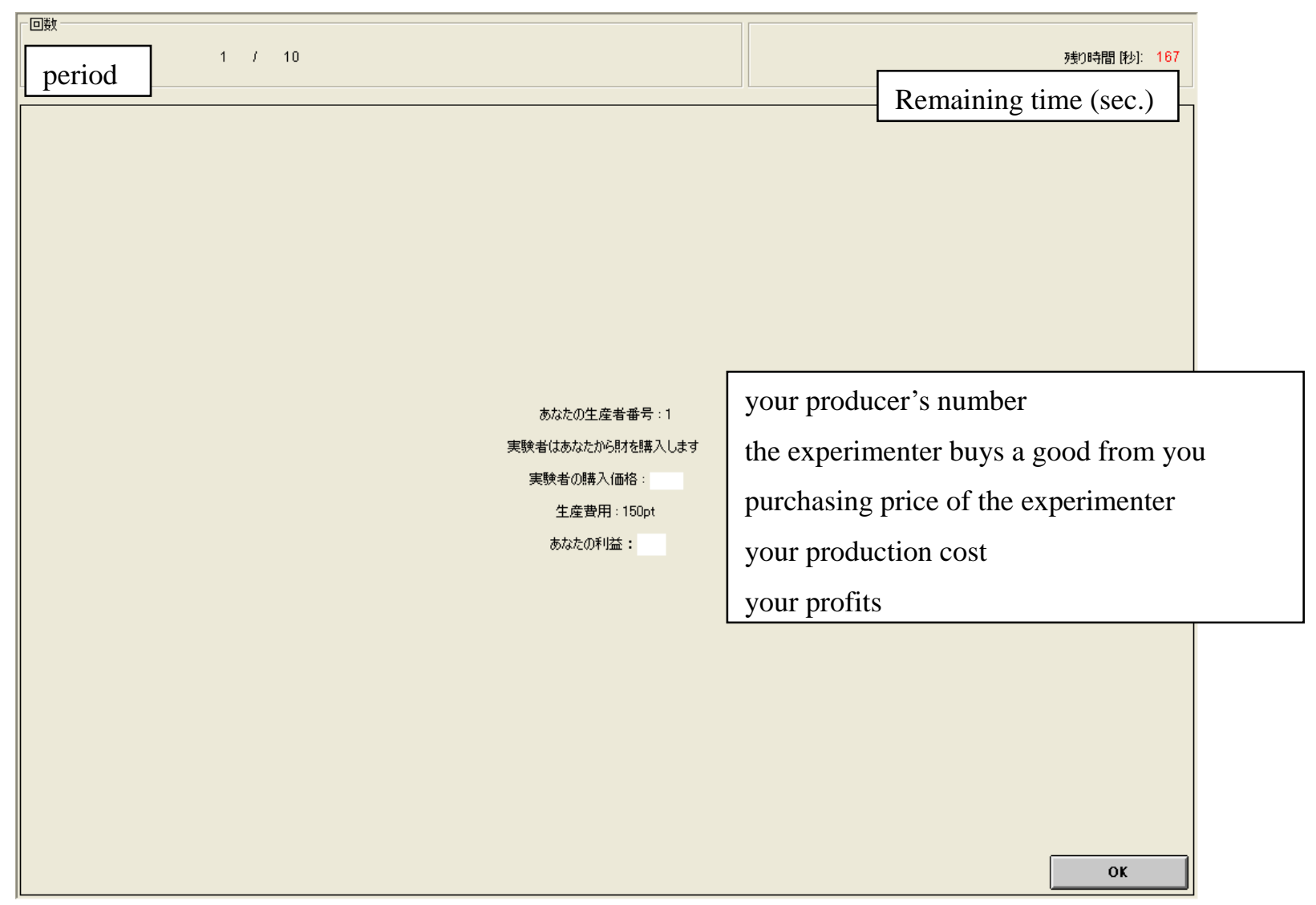

Screen 2

If the experimenter purchases the good from you, screen $\mathbf{2}$ is displayed. From the top of the display, "your producer's number", "the experimenter buys a good from you", "purchasing price of the experimenter", "production cost”, and "your profits” are displayed. In this example, the cell of “your producer's number” displays producer 1. Producer 1's production cost is 150 pt so that the cell of "your production cost” displays 150 pt. Numerical numbers are displayed in the white box cells of the right side of the "purchasing price of the experimenter" and "your profit". 
Every subject, in the actual experiment, transcribes the numerical number displayed at the right side of "your profit" on the record sheet. After the transcription, please click OK button in the lower-left corner of the screen.

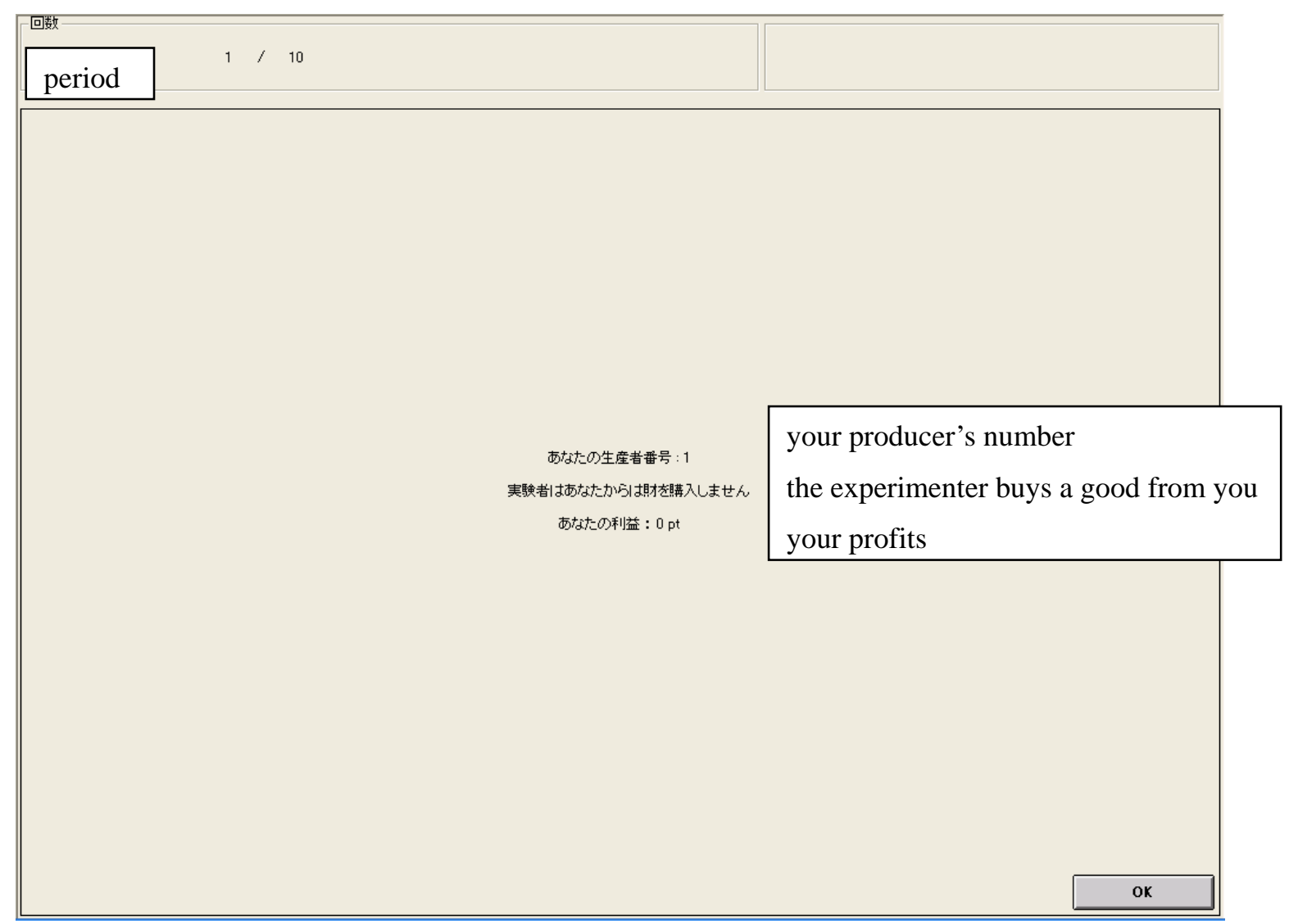

Screen 3

If the experimenter does not purchase the good from you, screen 3 is displayed. From the top of the display, "your producer's number", "the experimenter does not buy a good from you", "purchasing price of the experimenter", "production cost", and "your profits" are displayed. "Your profit" will be 0 pt.

Every subject, in the actual experiment, transcribes the numerical number displayed at the right side of "your profit" on the record sheet. After the transcription, please click OK button in the lower-left corner of the screen. 


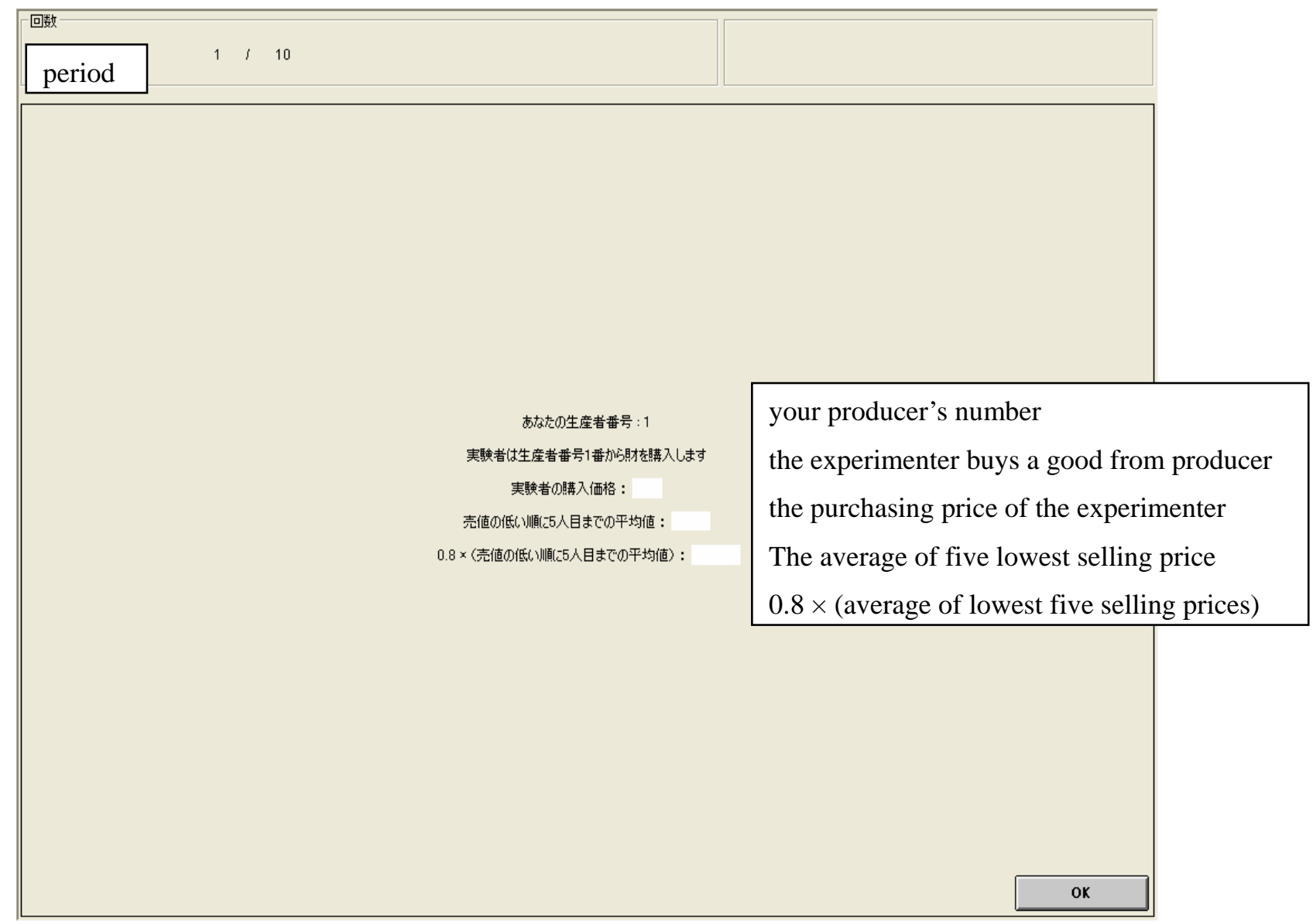

Screen 4

After the experimenter decides from whom he buy the good, he disclose "producer's identification number from whom the experimenter purchase a good", how much "the purchasing price of the experimenter" is, how much "average of five lowest selling prices" is, and how much " $0.8 \times$ (average of lowest five selling prices)" is. These information are displayed from the top of screen 4 . Here we show the case where we purchase the good from producer 1 as an example. Numerical numbers are displayed in the white box cells of the right side of the "purchasing price of the experimenter", "average of five lowest selling prices”, and “ $0.8 \times$ (average of lowest five selling prices)".

Every subject transcribes these information from the top on the cells of "producer's number from whom the experimenter purchased the good", "the purchasing price of the experimenter", “average of five lowest selling prices", and " $0.8 \times$ (average of lowest five selling prices)" in the record sheet. After the transcription, please click OK button in the lower-left corner of the screen. Once everybody click OK button, period 1 is completed and period 2 will start. The operation after period 2 is the same as one in period 1. The experiment is completed at the time when period 10 is completed. 
This is the end of explain the PC operation manuals. 


\section{All graphs in each cell}

In all graphs, the horizontal axis represents the number of periods, and vertical axis represents the price of bids. Winning bids are connected by a straight line, and these values are presented right next to the winning prices. Squares connected by a straight line represent the EMPs. In each graph of the identical condition, diamonds with numbers 1 to 10 represent bids of producers 1 to 10, respectively. In each graph of the different cost condition, diamonds with 2 (97), 5 (97), and 8 (97) represent bids of producers 2,5 and 8 whose costs are 97, respectively. Triangles with identification numbers $1,3,4,6,7,9$, and 10 represent bids of each producer whose cost is 150 . 
Figure S1. N-I-D

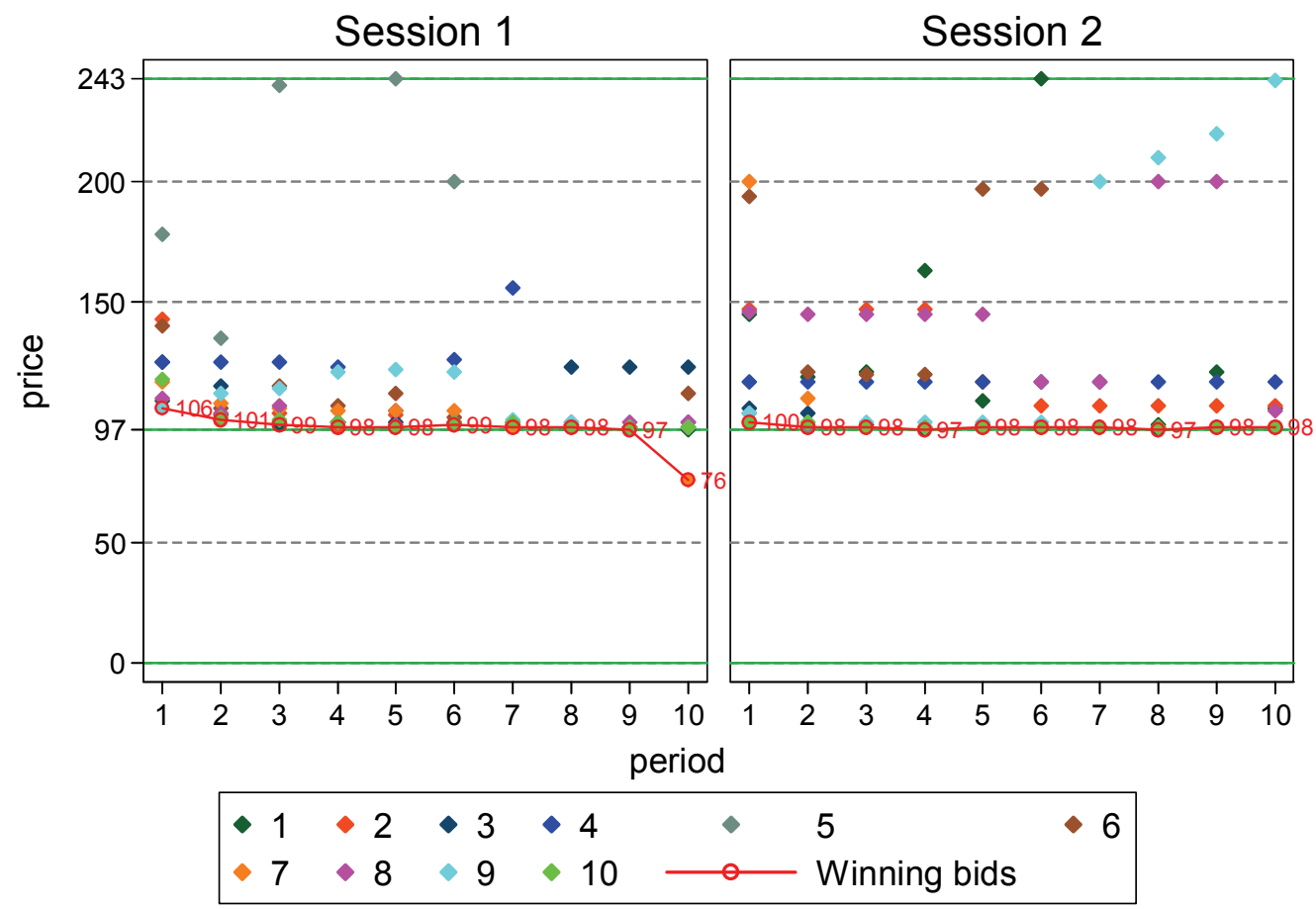

Figure S2. E-I-D

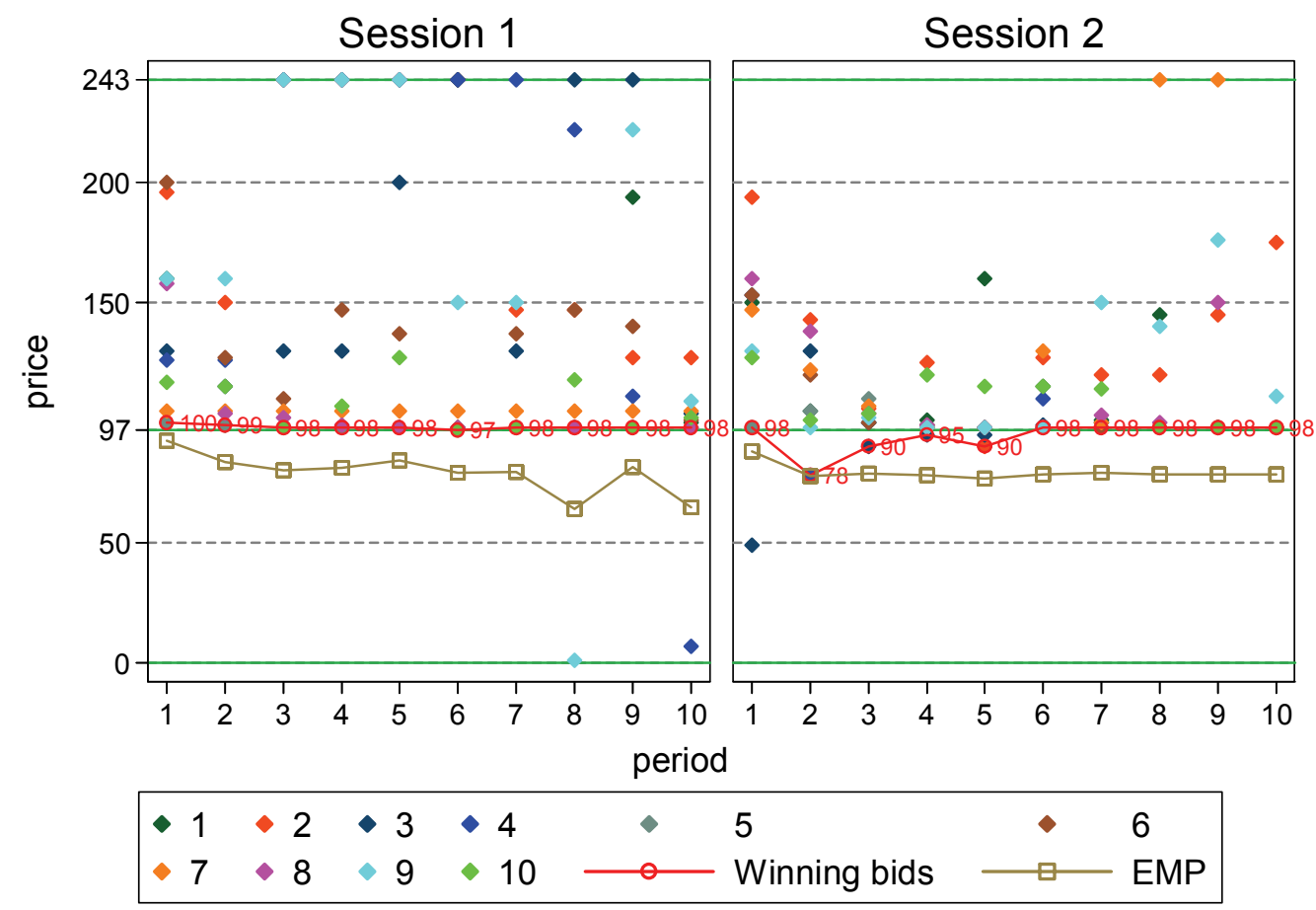


Figure S3. N-I-N

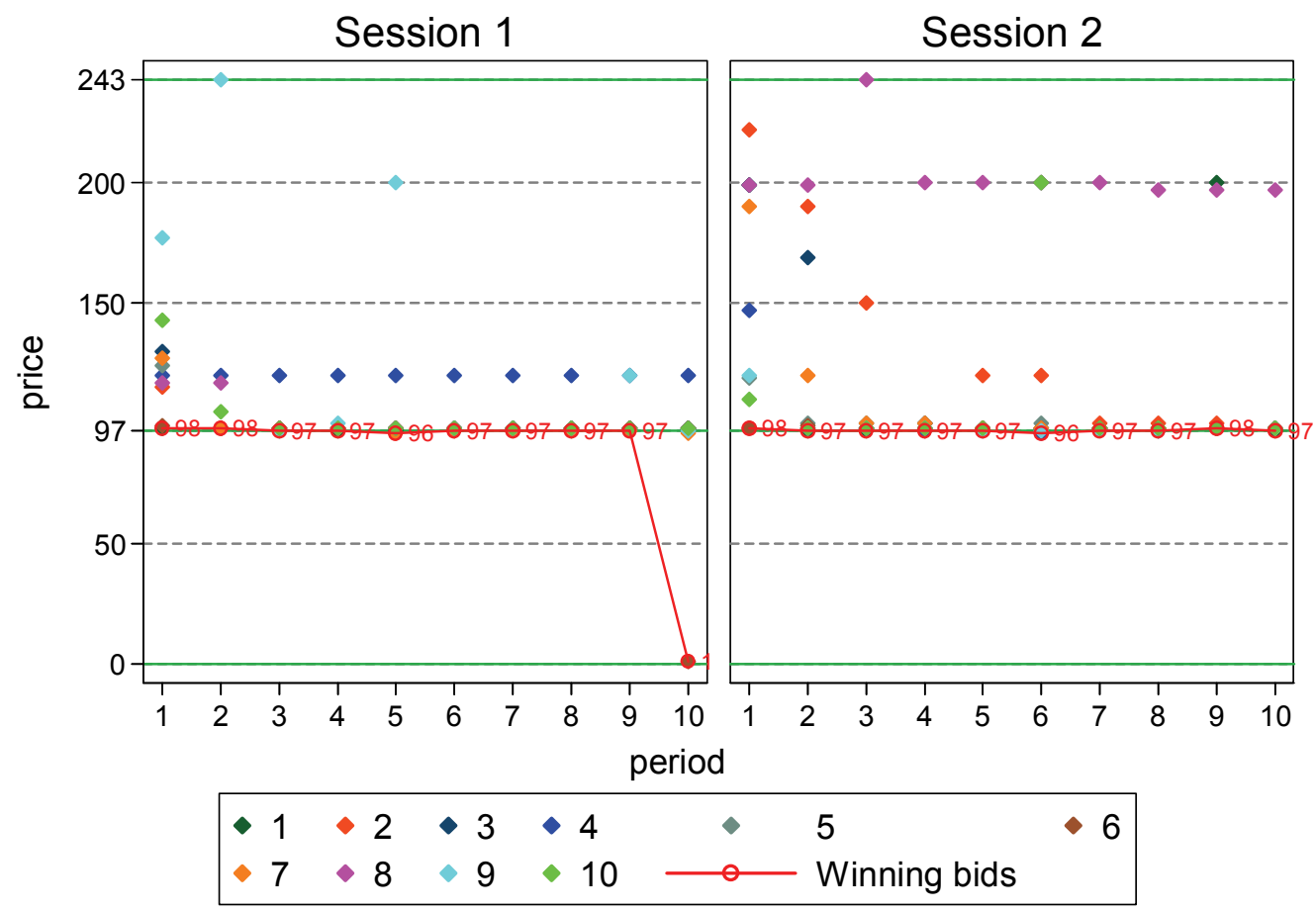

Figure S4. E-I-N

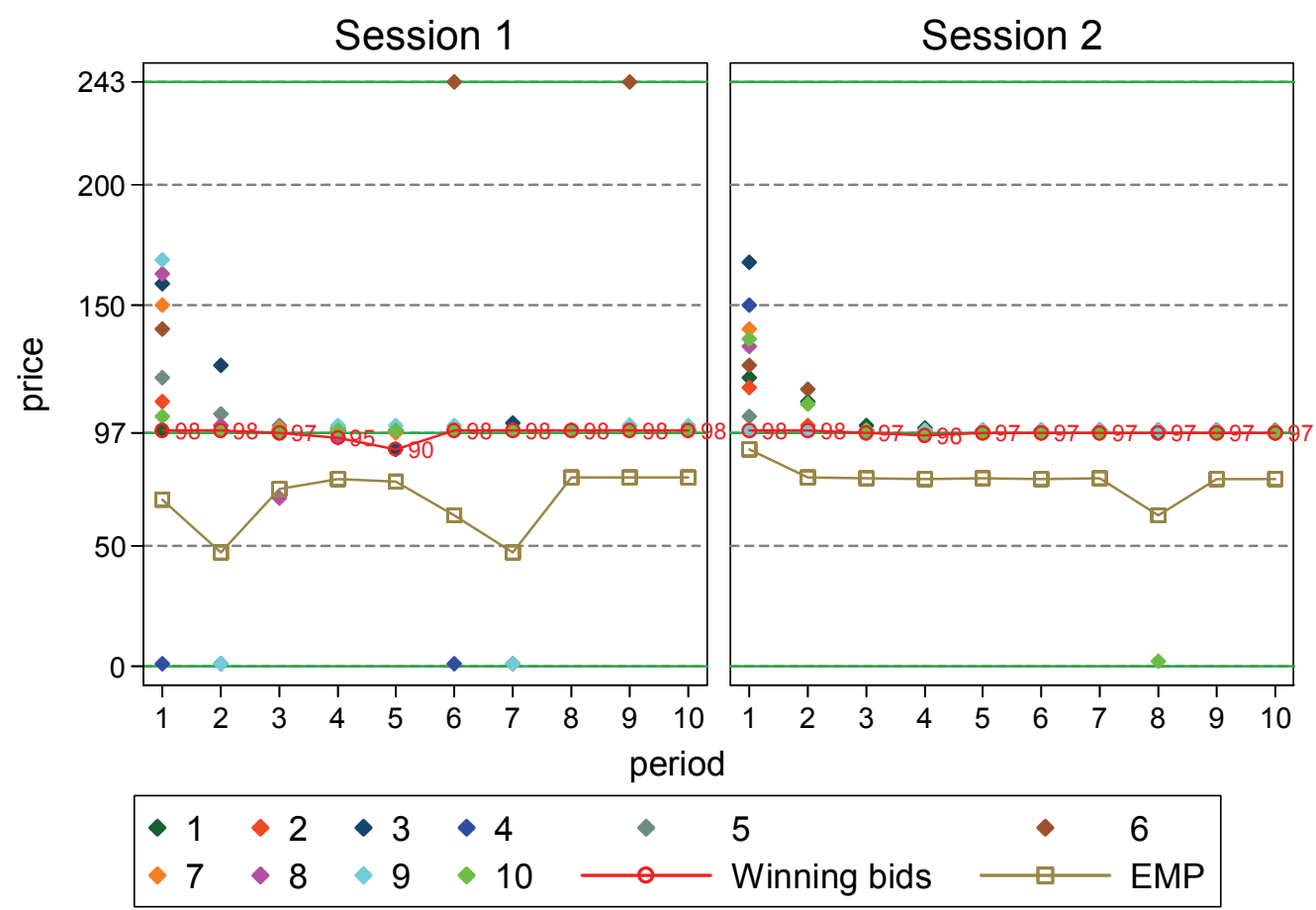


Figure S5. N-D-D

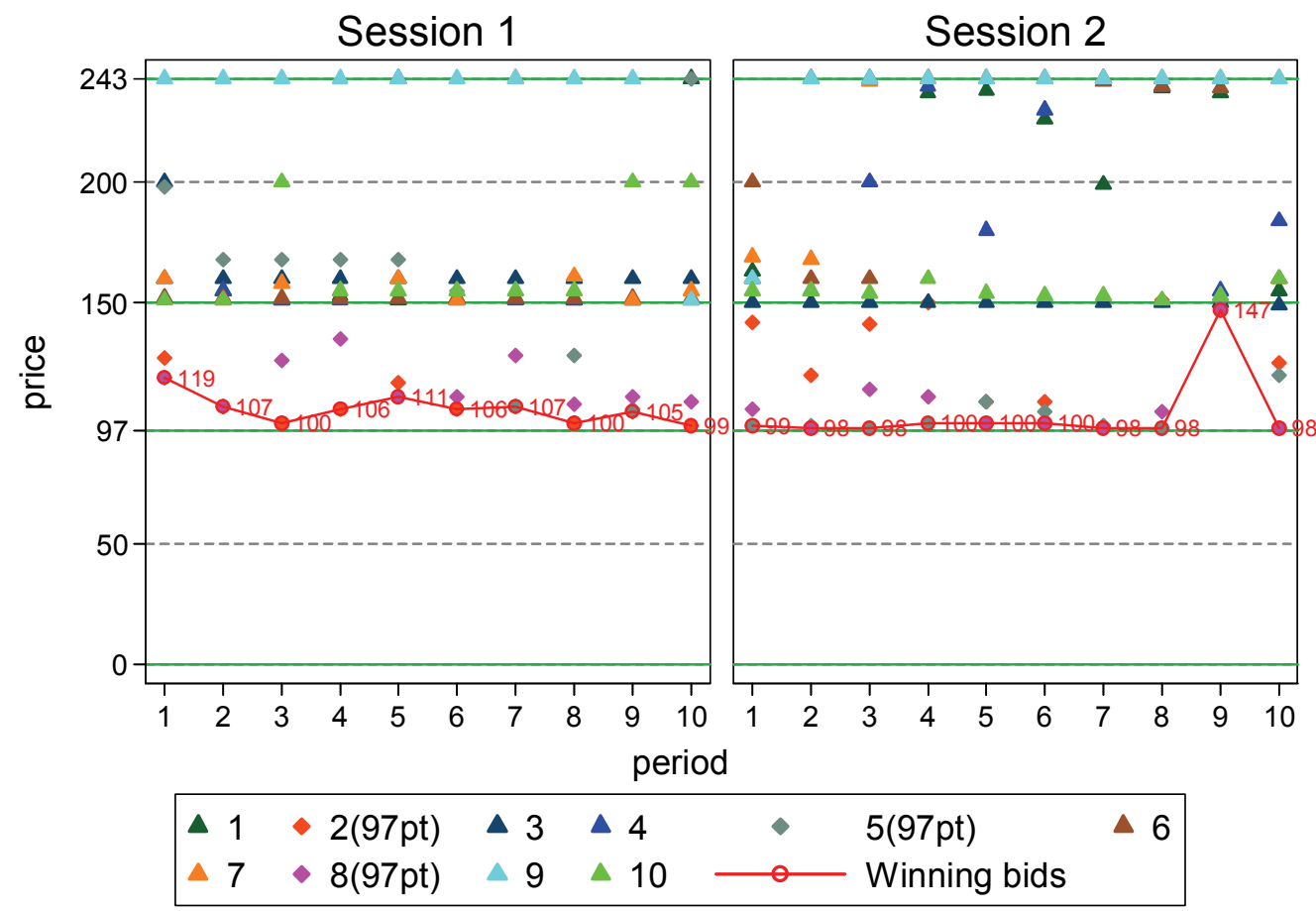

Figure S6. E-D-D

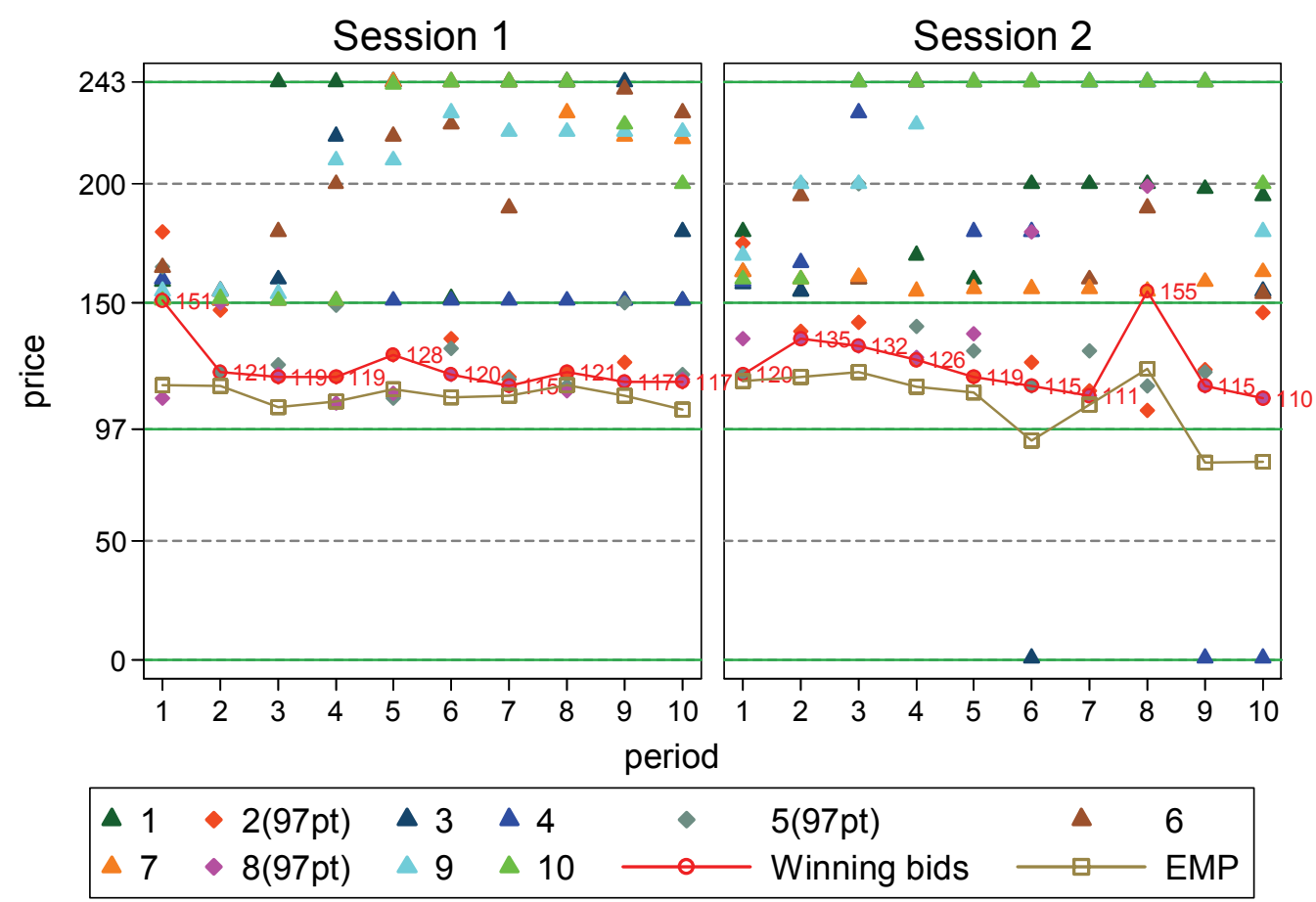


Figure S7. N-D-N

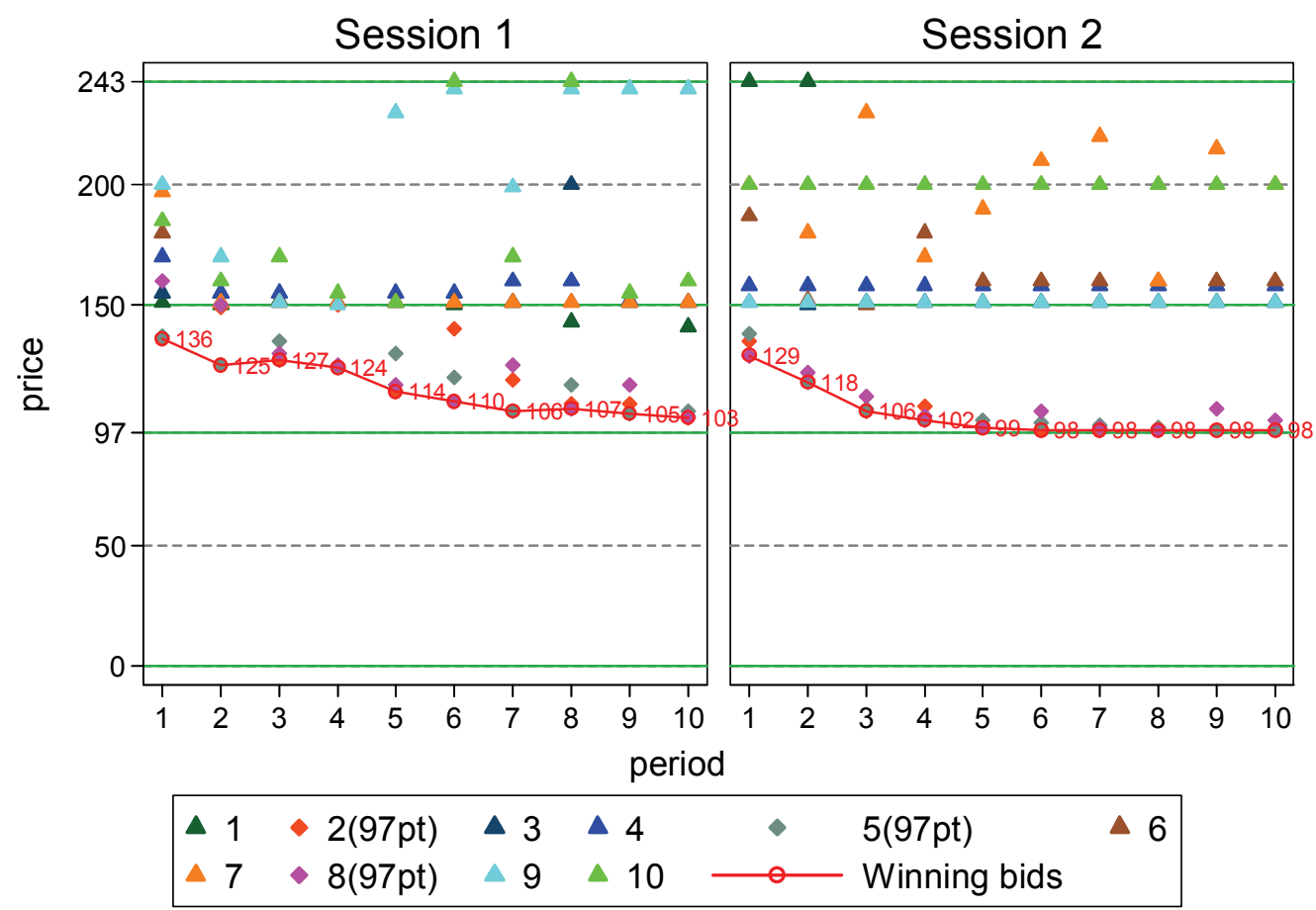

Figure S8. E-D-N

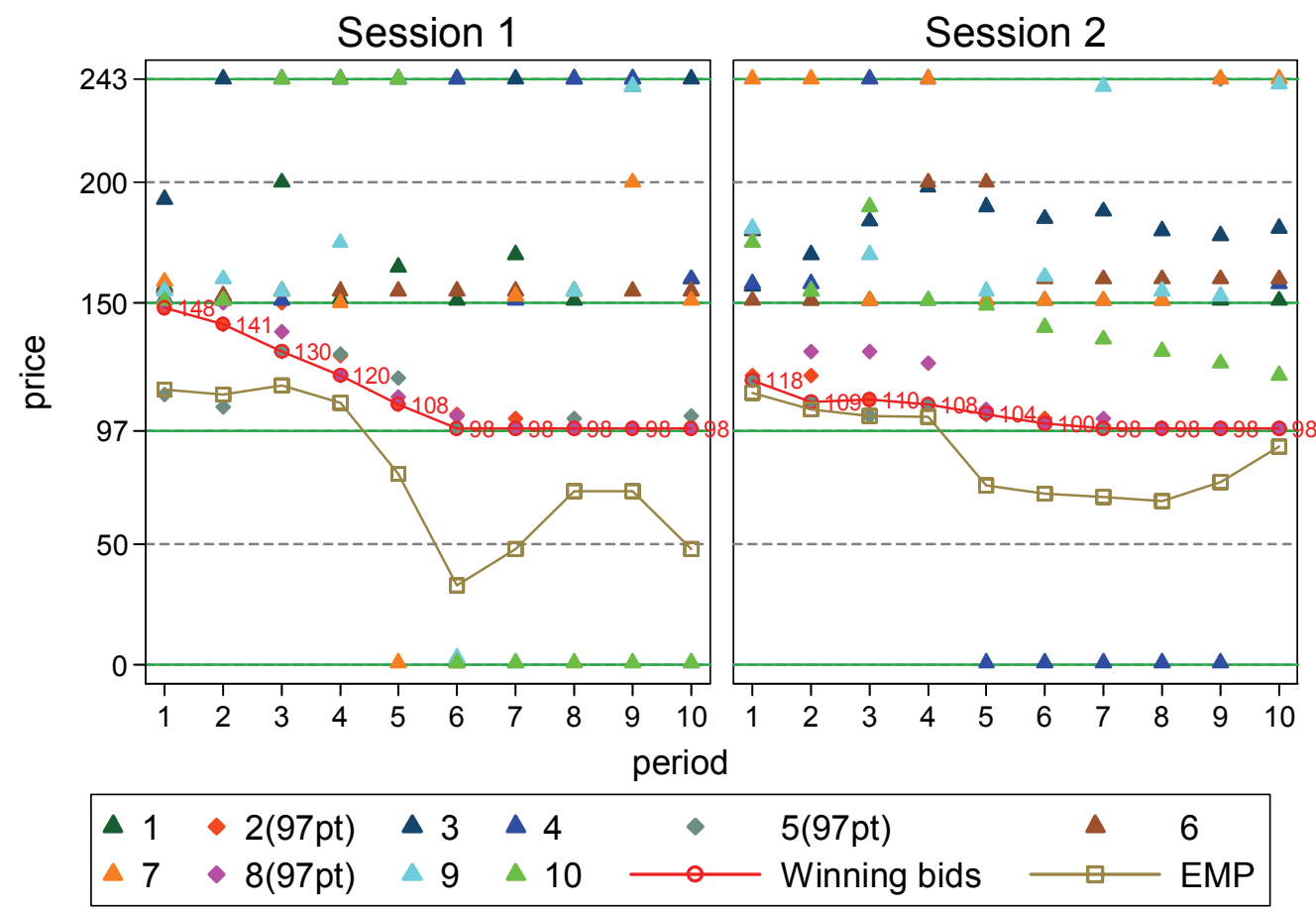




\begin{tabular}{|c|c|c|c|c|c|c|c|c|c|c|}
\hline \multirow[b]{2}{*}{ Producer's ID ( $\operatorname{cost})$} & \multicolumn{10}{|c|}{ Period } \\
\hline & 1 & 2 & 3 & 4 & 5 & 6 & 7 & 8 & 9 & 10 \\
\hline \multicolumn{11}{|l|}{ N-I-D: session 1} \\
\hline $1(97)$ & 109 & 103 & $99^{*}$ & 100 & $98^{*}$ & $99^{*}$ & 99 & 98 & 98 & 97 \\
\hline $2(97)$ & 143 & $101 *$ & 104 & $98^{*}$ & 103 & 99 & 99 & 98 & 98 & 98 \\
\hline $3(97)$ & 125 & 115 & 100 & 100 & 100 & 100 & 100 & 123 & 123 & 123 \\
\hline $4(97)$ & 125 & 125 & 125 & 123 & 105 & 126 & 156 & 99 & 98 & 100 \\
\hline $5(97)$ & 178 & 135 & 240 & 100 & 243 & 200 & 98 & 98 & 98 & 98 \\
\hline $6(97)$ & 140 & 106 & 115 & 107 & 112 & 102 & 99 & 99 & $97^{*}$ & 112 \\
\hline $7(97)$ & 117 & 108 & 106 & 105 & 105 & 105 & $98 *$ & 98 & 98 & $76^{*}$ \\
\hline $8(97)$ & 110 & 104 & 107 & 100 & 99 & 100 & 100 & 100 & 100 & 100 \\
\hline $9(97)$ & $106^{*}$ & 112 & 114 & 121 & 122 & 121 & 101 & 100 & 98 & 98 \\
\hline $10(97)$ & 118 & 102 & 101 & 100 & 98 & 100 & 100 & $98^{*}$ & 98 & 98 \\
\hline \multicolumn{11}{|l|}{ N-I-D: session 2} \\
\hline $1(97)$ & 145 & 119 & 121 & 163 & 109 & 243 & 98 & 99 & 121 & 106 \\
\hline $2(97)$ & 147 & 99 & 147 & 147 & 117 & 107 & 107 & 107 & 107 & 107 \\
\hline $3(97)$ & 106 & 104 & 99 & $97^{*}$ & 99 & 98 & $98^{*}$ & $97^{*}$ & 98 & 98 \\
\hline $4(97)$ & 117 & 117 & 117 & 117 & 117 & 117 & 117 & 117 & 117 & 117 \\
\hline $5(97)$ & 104 & $98^{*}$ & 98 & 98 & 98 & $98 *$ & 98 & 98 & 98 & 98 \\
\hline $6(97)$ & 194 & 121 & 120 & 120 & 197 & 197 & 98 & 98 & 98 & 98 \\
\hline 7 (97) & 200 & 110 & 98 & 98 & 98 & 98 & 98 & 98 & 98 & 98 \\
\hline $8(97)$ & 146 & 145 & 145 & 145 & 145 & 117 & 117 & 200 & 200 & 105 \\
\hline $9(97)$ & 104 & 100 & 100 & 100 & 100 & 100 & 200 & 210 & 220 & 242 \\
\hline $10(97)$ & $100^{*}$ & 100 & $98^{*}$ & 98 & $98^{*}$ & 98 & 98 & 98 & $98^{*}$ & $98^{*}$ \\
\hline \multicolumn{11}{|l|}{ N-I-N: session 1} \\
\hline $1(97)$ & $98^{*}$ & 98 & 97 & $97^{*}$ & 97 & $97^{*}$ & 98 & $97^{*}$ & 98 & 98 \\
\hline $2(97)$ & 115 & $98^{*}$ & 98 & 98 & 98 & 98 & 98 & 98 & 98 & 98 \\
\hline $3(97)$ & 130 & 98 & 98 & 98 & 98 & 98 & 98 & 98 & 98 & 98 \\
\hline $4(97)$ & 120 & 120 & 120 & 120 & 120 & 120 & 120 & 120 & 120 & 120 \\
\hline $5(97)$ & 124 & 98 & 98 & 98 & 98 & 98 & 98 & 98 & 98 & 98 \\
\hline $6(97)$ & 99 & 98 & 98 & 98 & 98 & 98 & 98 & 98 & 98 & $1^{*}$ \\
\hline $7(97)$ & 127 & 98 & 98 & 98 & $96^{*}$ & 97 & $97 *$ & 97 & $97 *$ & 96 \\
\hline $8(97)$ & 117 & 117 & 98 & 98 & 98 & 98 & 98 & 98 & 98 & 98 \\
\hline $9(97)$ & 177 & 243 & $97^{*}$ & 100 & 200 & 98 & 98 & 98 & 120 & 97 \\
\hline $10(97)$ & 143 & 105 & 98 & 98 & 98 & 98 & 98 & 98 & 98 & 98 \\
\hline \multicolumn{11}{|l|}{ N-I-N: session 2} \\
\hline $1(97)$ & 199 & $97^{*}$ & $97 *$ & 98 & 98 & 200 & 98 & 97 & 200 & $97 *$ \\
\hline $2(97)$ & 222 & 190 & 150 & $97 *$ & 120 & 120 & 100 & 100 & 100 & 98 \\
\hline $3(97)$ & 199 & 169 & 98 & 100 & 98 & 98 & 98 & 98 & 98 & 98 \\
\hline $4(97)$ & 147 & 98 & 98 & 97 & 97 & $96^{*}$ & 98 & $97 *$ & 98 & 98 \\
\hline $5(97)$ & 119 & 100 & 100 & 100 & 98 & 100 & 98 & 98 & 98 & 98 \\
\hline $6(97)$ & $98^{*}$ & 99 & 98 & 98 & 98 & 98 & 98 & 98 & 98 & 98 \\
\hline 7 (97) & 190 & 120 & 100 & 100 & 98 & 98 & 98 & 98 & $98 *$ & 98 \\
\hline $8(97)$ & 199 & 199 & 243 & 200 & 200 & 200 & 200 & 197 & 197 & 197 \\
\hline $9(97)$ & 120 & 98 & 98 & 98 & $97^{*}$ & 97 & $97^{*}$ & 97 & 98 & 98 \\
\hline $10(97)$ & 110 & 98 & 98 & 98 & 98 & 200 & 98 & 98 & 98 & 98 \\
\hline
\end{tabular}

* shows the winning bids. 


\begin{tabular}{|c|c|c|c|c|c|c|c|c|c|c|}
\hline \multirow[b]{2}{*}{ Producer's ID (cost) } & \multicolumn{10}{|c|}{ Period } \\
\hline & 1 & 2 & 3 & 4 & 5 & 6 & 7 & 8 & 9 & 10 \\
\hline \multicolumn{11}{|l|}{ N-D-D: session 1} \\
\hline $1(150)$ & 152 & 155 & 151 & 153 & 151 & 152 & 152 & 151 & 151 & 243 \\
\hline $2(97)$ & 127 & $107^{*}$ & $100^{*}$ & $106^{*}$ & 117 & $106^{*}$ & 107 & $100^{*}$ & $105^{*}$ & $99 *$ \\
\hline $3(150)$ & 200 & 160 & 160 & 160 & 160 & 160 & 160 & 160 & 160 & 160 \\
\hline $4(150)$ & 160 & 155 & 151 & 151 & 243 & 151 & 151 & 151 & 151 & 151 \\
\hline $5(97)$ & 198 & 168 & 168 & 168 & 168 & 155 & $107^{*}$ & 128 & 106 & 243 \\
\hline $6(150)$ & 152 & 152 & 152 & 152 & 152 & 152 & 152 & 152 & 152 & 152 \\
\hline $7(150)$ & 160 & 151 & 158 & 155 & 160 & 151 & 243 & 161 & 151 & 155 \\
\hline $8(97)$ & $119^{*}$ & 107 & 126 & 135 & $111^{*}$ & 111 & 128 & 108 & 111 & 109 \\
\hline $9(150)$ & 243 & 243 & 243 & 243 & 243 & 243 & 243 & 243 & 243 & 151 \\
\hline $10(150)$ & 151 & 151 & 200 & 155 & 155 & 155 & 155 & 155 & 200 & 200 \\
\hline \multicolumn{11}{|l|}{ N-D-D: session 2} \\
\hline $1(150)$ & 163 & 243 & 243 & 237 & 238 & 226 & 199 & 239 & 237 & 155 \\
\hline $2(97)$ & 142 & 120 & 141 & 150 & 109 & 109 & 151 & 151 & 149 & 125 \\
\hline $3(150)$ & 150 & 150 & 150 & 150 & 150 & 150 & 150 & 150 & 150 & 149 \\
\hline $4(150)$ & 160 & 155 & 200 & 240 & 180 & 230 & 243 & 240 & 155 & 184 \\
\hline $5(97)$ & $99 *$ & 99 & $98 *$ & $100^{*}$ & 109 & 105 & 99 & $98^{*}$ & 151 & 120 \\
\hline $6(150)$ & 200 & 160 & 160 & 243 & 243 & 243 & 242 & 240 & 239 & 160 \\
\hline $7(150)$ & 169 & 168 & 242 & 243 & 243 & 243 & 243 & 243 & 243 & 243 \\
\hline $8(97)$ & 106 & $98^{*}$ & 114 & 111 & $100^{*}$ & $100^{*}$ & $98^{*}$ & 105 & $147^{*}$ & $98^{*}$ \\
\hline $9(150)$ & 160 & 243 & 243 & 243 & 243 & 243 & 243 & 243 & 243 & 243 \\
\hline $10(150)$ & 155 & 155 & 154 & 160 & 154 & 153 & 153 & 151 & 153 & 160 \\
\hline \multicolumn{11}{|l|}{ N-D-N: session 1} \\
\hline $1(150)$ & 151 & 150 & 152 & 151 & 151 & 150 & 151 & 143 & 151 & 141 \\
\hline $2(97)$ & $136^{*}$ & 149 & $127^{*}$ & 150 & $114^{*}$ & 140 & 119 & 109 & 109 & $103^{*}$ \\
\hline $3(150)$ & 155 & 155 & 151 & 151 & 151 & 151 & 151 & 200 & 151 & 151 \\
\hline $4(150)$ & 170 & 155 & 155 & 151 & 155 & 155 & 160 & 160 & 152 & 151 \\
\hline $5(97)$ & 137 & $125^{*}$ & 135 & $124 *$ & 130 & 120 & $106^{*}$ & 117 & $105^{*}$ & 106 \\
\hline $6(150)$ & 180 & 151 & 151 & 151 & 151 & 151 & 151 & 151 & 151 & 151 \\
\hline $7(150)$ & 197 & 151 & 151 & 151 & 151 & 151 & 151 & 151 & 151 & 151 \\
\hline $8(97)$ & 160 & 150 & 130 & 125 & 117 & $110^{*}$ & 125 & $107 *$ & 117 & 104 \\
\hline $9(150)$ & 200 & 170 & 151 & 150 & 230 & 240 & 199 & 240 & 240 & 240 \\
\hline $10(150)$ & 185 & 160 & 170 & 155 & 151 & 243 & 170 & 243 & 155 & 160 \\
\hline \multicolumn{11}{|l|}{ N-D-N: session 2} \\
\hline $1(150)$ & 243 & 243 & 151 & 151 & 151 & 151 & 151 & 151 & 151 & 151 \\
\hline $2(97)$ & 135 & 119 & $106^{*}$ & 108 & 100 & $98^{*}$ & $98^{*}$ & 99 & $98^{*}$ & 98 \\
\hline $3(150)$ & 151 & 150 & 151 & 151 & 151 & 151 & 151 & 151 & 151 & 151 \\
\hline $4(150)$ & 158 & 158 & 158 & 158 & 158 & 158 & 158 & 158 & 158 & 158 \\
\hline $5(97)$ & 138 & $118^{*}$ & 107 & $102 *$ & 102 & 101 & 100 & 99 & 98 & $98^{*}$ \\
\hline $6(150)$ & 187 & 152 & 150 & 180 & 160 & 160 & 160 & 160 & 160 & 160 \\
\hline $7(150)$ & 200 & 180 & 230 & 170 & 190 & 210 & 220 & 160 & 215 & 200 \\
\hline $8(97)$ & $129 *$ & 122 & 112 & 104 & $99 *$ & 106 & 99 & $98 *$ & 107 & 102 \\
\hline $9(150)$ & 151 & 151 & 151 & 151 & 151 & 151 & 151 & 151 & 151 & 151 \\
\hline $10(150)$ & 200 & 200 & 200 & 200 & 200 & 200 & 200 & 200 & 200 & 200 \\
\hline
\end{tabular}

* shows the winning bids. 


\begin{tabular}{|c|c|c|c|c|c|c|c|c|c|c|}
\hline \multirow[b]{2}{*}{ Producer's ID (cost) } & \multicolumn{10}{|c|}{ Period } \\
\hline & 1 & 2 & 3 & 4 & 5 & 6 & 7 & 8 & 9 & 10 \\
\hline \multicolumn{11}{|l|}{ E-I-D: session 1} \\
\hline $1(97)$ & 160 & $99 *$ & 98 & $98^{*}$ & $98^{*}$ & 243 & 98 & $98^{*}$ & 194 & 100 \\
\hline $2(97)$ & 196 & 150 & 243 & 243 & 243 & 243 & 147 & 147 & 127 & 127 \\
\hline $3(97)$ & 130 & 115 & 130 & 130 & 200 & 243 & 130 & 243 & 243 & 104 \\
\hline $4(97)$ & 126 & 126 & 243 & 243 & 243 & 243 & 243 & 222 & 111 & 7 \\
\hline $5(97)$ & $100 *$ & 99 & 98 & 98 & 98 & 98 & 98 & 98 & 98 & 98 \\
\hline $6(97)$ & 200 & 127 & 110 & 147 & 137 & 98 & 137 & 147 & 140 & 101 \\
\hline $7(97)$ & 105 & 105 & 105 & 105 & 105 & 105 & 105 & 105 & 105 & 105 \\
\hline $8(97)$ & 158 & 104 & 102 & 99 & 98 & 98 & 98 & 98 & 98 & $98^{*}$ \\
\hline $9(97)$ & 160 & 160 & 243 & 243 & 243 & 150 & 150 & 1 & 222 & 109 \\
\hline $10(97)$ & 117 & 115 & $98^{*}$ & 107 & 127 & $97 *$ & $98^{*}$ & 118 & $98^{*}$ & 102 \\
\hline EMP & 92.5 & 83.5 & 80.2 & 81.1 & 84.2 & 79.4 & 79.5 & 64 & 81.6 & 64.6 \\
\hline \multicolumn{11}{|l|}{ E-I-D: session 2} \\
\hline $1(97)$ & 150 & 105 & 100 & 101 & 160 & 115 & 101 & 145 & 98 & 98 \\
\hline $2(97)$ & 194 & 143 & 106 & 125 & $90^{*}$ & 127 & 120 & 120 & 145 & 175 \\
\hline $3(97)$ & 49 & 130 & $90 *$ & $95^{*}$ & 95 & 99 & 100 & 98 & $98^{*}$ & 98 \\
\hline $4(97)$ & 153 & $78^{*}$ & 100 & 98 & 98 & 110 & 98 & $98 *$ & 98 & 98 \\
\hline $5(97)$ & $98^{*}$ & 105 & 110 & 99 & 98 & 98 & $98^{*}$ & 98 & 98 & 98 \\
\hline $6(97)$ & 153 & 120 & 100 & 99 & 98 & 98 & 98 & 98 & 98 & 98 \\
\hline 7 (97) & 147 & 122 & 107 & 98 & 98 & 130 & 100 & 243 & 243 & $98^{*}$ \\
\hline $8(97)$ & 160 & 138 & 104 & 99 & 98 & $98^{*}$ & 103 & 100 & 150 & 98 \\
\hline $9(97)$ & 130 & 98 & 102 & 98 & 98 & 98 & 150 & 140 & 176 & 111 \\
\hline $10(97)$ & 127 & 101 & 104 & 120 & 115 & 115 & 114 & 98 & 98 & 98 \\
\hline EMP & 88.2 & 77.9 & 78.7 & 78.1 & 76.6 & 78.6 & 79 & 78.4 & 78.4 & 78.4 \\
\hline \multicolumn{11}{|l|}{ E-I-N: session 1} \\
\hline $1(97)$ & $98^{*}$ & 98 & 98 & 98 & 98 & 98 & 98 & 98 & 98 & 98 \\
\hline $2(97)$ & 110 & 98 & 98 & 98 & 98 & 98 & 98 & 98 & 98 & 98 \\
\hline $3(97)$ & 159 & 125 & 98 & 98 & $90^{*}$ & $98 *$ & 101 & 98 & $98 *$ & 98 \\
\hline $4(97)$ & 1 & 1 & 98 & 98 & 98 & 1 & 98 & $98 *$ & 98 & 98 \\
\hline $5(97)$ & 120 & 105 & 100 & 99 & 98 & 98 & $98 *$ & 98 & 100 & 98 \\
\hline $6(97)$ & 140 & 98 & $97^{*}$ & 99 & 98 & 243 & 1 & 98 & 243 & 98 \\
\hline 7 (97) & 150 & 100 & 99 & 99 & 97 & 98 & 98 & 98 & 98 & 99 \\
\hline $8(97)$ & 163 & 100 & 70 & $95^{*}$ & 98 & 98 & 98 & 98 & 98 & $98^{*}$ \\
\hline $9(97)$ & 169 & 1 & 98 & 100 & 100 & 100 & 1 & 98 & 100 & 100 \\
\hline $10(97)$ & 104 & $98^{*}$ & 98 & 98 & 98 & 98 & 98 & 98 & 98 & 98 \\
\hline EMP & 69.3 & 47.4 & 73.8 & 77.9 & 77 & 62.9 & 47.4 & 78.4 & 78.4 & 78.4 \\
\hline \multicolumn{11}{|l|}{ E-I-N: session 2} \\
\hline $1(97)$ & 120 & 110 & 100 & 99 & 98 & 97 & 97 & $97 *$ & $97 *$ & 97 \\
\hline $2(97)$ & 116 & 100 & 98 & 98 & 98 & 98 & 98 & 98 & 98 & 98 \\
\hline $3(97)$ & 168 & 98 & 98 & 98 & 98 & $97 *$ & 98 & 98 & 98 & 98 \\
\hline $4(97)$ & 150 & 98 & 98 & 98 & 98 & 98 & 98 & 98 & 98 & 98 \\
\hline $5(97)$ & 104 & $98 *$ & $97 *$ & 97 & $97 *$ & 97 & 98 & 98 & 98 & 98 \\
\hline $6(97)$ & 125 & 115 & 98 & 98 & 98 & 98 & 98 & 98 & 98 & $97 *$ \\
\hline 7 (97) & 140 & 98 & 98 & 98 & 98 & 98 & 98 & 98 & 97 & 97 \\
\hline $8(97)$ & 133 & 98 & 98 & 98 & 98 & 98 & 98 & 98 & 98 & 98 \\
\hline $9(97)$ & $98 *$ & 98 & 98 & 98 & 98 & 98 & 98 & 98 & 98 & 98 \\
\hline $10(97)$ & 136 & 109 & 98 & $96 *$ & 97 & 97 & $97^{*}$ & 2 & 97 & 98 \\
\hline EMP & 90.1 & 78.4 & 78.2 & 77.9 & 78.1 & 77.8 & 78.1 & 62.9 & 77.9 & 77.9 \\
\hline
\end{tabular}

* shows the winning bids. 


\begin{tabular}{|c|c|c|c|c|c|c|c|c|c|c|}
\hline \multirow[b]{2}{*}{ Producer's ID (cost) } & \multicolumn{10}{|c|}{ Period } \\
\hline & 1 & 2 & 3 & 4 & 5 & 6 & 7 & 8 & 9 & 10 \\
\hline \multicolumn{11}{|l|}{ E-D-D: session 1} \\
\hline $1(150)$ & 159 & 151 & 243 & 243 & 243 & 152 & 243 & 243 & 151 & 151 \\
\hline $2(97)$ & 180 & 147 & $119^{*}$ & $119^{*}$ & $128^{*}$ & 135 & 119 & $121^{*}$ & 125 & $117^{*}$ \\
\hline $3(150)$ & 153 & 155 & 160 & 220 & 243 & 243 & 243 & 243 & 243 & 180 \\
\hline $4(150)$ & 160 & 151 & 151 & 151 & 151 & 151 & 151 & 151 & 151 & 151 \\
\hline $5(97)$ & 165 & $121 *$ & 124 & 149 & 110 & 131 & 118 & 115 & 150 & 120 \\
\hline $6(150)$ & 165 & 155 & 180 & 200 & 220 & 225 & 190 & 243 & 240 & 230 \\
\hline $7(150)$ & 152 & 151 & 151 & 151 & 243 & 243 & 243 & 230 & 220 & 219 \\
\hline $8(97)$ & 110 & 150 & 120 & 108 & 112 & $120 *$ & $115^{*}$ & 113 & $117^{*}$ & 118 \\
\hline $9(150)$ & 155 & 155 & 154 & 210 & 210 & 230 & 222 & 222 & 222 & 222 \\
\hline $10(150)$ & $151^{*}$ & 152 & 151 & 151 & 242 & 243 & 243 & 243 & 225 & 200 \\
\hline EMP & 115 & 115 & 106 & 108 & 114 & 110 & 111 & 116 & 111 & 105 \\
\hline \multicolumn{11}{|l|}{ E-D-D: session 2} \\
\hline $1(150)$ & 180 & 155 & 160 & 170 & 160 & 200 & 200 & 200 & 198 & 195 \\
\hline $2(97)$ & 175 & 138 & 142 & $126^{*}$ & $119^{*}$ & 125 & 113 & 105 & 122 & 146 \\
\hline $3(150)$ & 158 & 155 & 243 & 243 & 243 & 1 & 243 & 243 & 243 & 155 \\
\hline $4(150)$ & 159 & 167 & 230 & 243 & 180 & 180 & 243 & 243 & 1 & 1 \\
\hline $5(97)$ & $120 *$ & 200 & 200 & 140 & 130 & $115^{*}$ & 130 & 115 & 121 & 110 \\
\hline $6(150)$ & 163 & 195 & 160 & 243 & 243 & 243 & 160 & 190 & 243 & 154 \\
\hline $7(150)$ & 163 & 160 & 161 & 155 & 156 & 156 & 156 & $155^{*}$ & 159 & 163 \\
\hline $8(97)$ & 135 & $135^{*}$ & $132 *$ & 127 & 137 & 180 & $111^{*}$ & 199 & $115^{*}$ & $110^{*}$ \\
\hline $9(150)$ & 170 & 200 & 200 & 225 & 243 & 243 & 243 & 243 & 243 & 180 \\
\hline $10(150)$ & 160 & 160 & 243 & 243 & 243 & 243 & 243 & 243 & 243 & 200 \\
\hline EMP & 117 & 119 & 121 & 115 & 112 & 92.3 & 107 & 122 & 82.9 & 83.4 \\
\hline \multicolumn{11}{|l|}{ E-D-N: session 1} \\
\hline $1(150)$ & 157 & 153 & 200 & 152 & 165 & 151 & 170 & 151 & 240 & 160 \\
\hline $2(97)$ & $148^{*}$ & $141^{*}$ & 150 & 128 & $108 *$ & 104 & 102 & $98^{*}$ & 98 & $98^{*}$ \\
\hline $3(150)$ & 193 & 243 & 243 & 243 & 243 & 243 & 243 & 243 & 243 & 243 \\
\hline $4(150)$ & 152 & 151 & 151 & 243 & 243 & 243 & 151 & 243 & 243 & 160 \\
\hline $5(97)$ & 112 & 107 & $130 *$ & 129 & 119 & $98^{*}$ & 98 & 102 & $98^{*}$ & 103 \\
\hline $6(150)$ & 156 & 153 & 155 & 155 & 155 & 155 & 155 & 155 & 155 & 155 \\
\hline $7(150)$ & 159 & 151 & 155 & 150 & 1 & 1 & 153 & 155 & 200 & 151 \\
\hline $8(97)$ & 150 & 150 & 138 & $120^{*}$ & 111 & 103 & $98^{*}$ & 98 & 98 & 98 \\
\hline $9(150)$ & 155 & 160 & 155 & 175 & 243 & 3 & 1 & 155 & 240 & 1 \\
\hline $10(150)$ & 151 & 151 & 243 & 243 & 243 & 1 & 1 & 1 & 1 & 1 \\
\hline EMP & 114 & 112 & 116 & 109 & 79 & 33 & 48 & 72 & 72 & 48.2 \\
\hline \multicolumn{11}{|l|}{ E-D-N: session 2} \\
\hline $1(150)$ & 180 & 151 & 151 & 151 & 151 & 151 & 151 & 151 & 151 & 151 \\
\hline $2(97)$ & 120 & 120 & $110^{*}$ & 108 & $104 *$ & 102 & 99 & 98 & $98 *$ & $98^{*}$ \\
\hline $3(150)$ & 157 & 170 & 184 & 198 & 190 & 185 & 188 & 180 & 178 & 181 \\
\hline $4(150)$ & 158 & 158 & 243 & 243 & 1 & 1 & 1 & 1 & 1 & 158 \\
\hline $5(97)$ & $118^{*}$ & $109 *$ & 103 & $108^{*}$ & 104 & 100 & $98^{*}$ & 98 & 243 & 98 \\
\hline $6(150)$ & 151 & 151 & 151 & 200 & 200 & 160 & 160 & 160 & 160 & 160 \\
\hline $7(150)$ & 243 & 243 & 151 & 243 & 151 & 151 & 151 & 151 & 243 & 243 \\
\hline $8(97)$ & 180 & 130 & 130 & 125 & 106 & $100 *$ & 102 & $98^{*}$ & 98 & 98 \\
\hline $9(150)$ & 181 & 155 & 170 & 151 & 155 & 161 & 240 & 155 & 153 & 241 \\
\hline $10(150)$ & 175 & 155 & 190 & 151 & 149 & 140 & 135 & 130 & 125 & 120 \\
\hline EMP & 113 & 106 & 103 & 103 & 74.2 & 70.9 & 69.6 & 68 & 75.7 & 90.4 \\
\hline
\end{tabular}

* shows the winning bids. 